Estudios Constitucionales, Año 12, No 2, 2014, pp. 55-108.

ISSN 07180195

Centro de Estudios Constitucionales de Chile Universidad de Talca

"Constitución y relaciones entre ordenamientos en el contexto de la globalización"

Juan Francisco Sánchez Barrilao

\title{
CONSTITUCIÓN Y RELACIONES ENTRE ORDENAMIENTOS EN EL CONTEXTO DE LA GLOBALIZACIÓN* \\ CONSTITUTION AND RELATIONSHIPS BETWEEN \\ LEGAL SYSTEMS IN THE CONTEXT OF GLOBALIZATION
}

\author{
Juan Francisco Sánchez Barrilao ${ }^{*}$ \\ Profesor Titular de Derecho Constitucional \\ Universidad de Granada \\ juanfco@ugr.es
}

RESUMEN: El trabajo tiene por objeto el estudio de las relaciones entre ordenamientos en el contexto de la globalización; y ello, desde la perspectiva del Derecho constitucional. Se comienza presentando las transformaciones que para el Derecho supone la globalización, para seguidamente entrar en los distintos tipos de ordenamientos que cabe advertir; y esto, además, desde la capacidad conformadora y sistemática que aún supone la Constitución normativa respecto a los ordenamientos estatales. Luego, se procede al análisis específico de las relaciones entre ordenamientos jurídicos, empezando por enfatizar la idea de pluralismo, seguidamente indicando diversos grados de relación entre ordenamientos, para finalmente concretar en la articulación jurídica de las relaciones entre ordenamientos según sean relaciones especificas (mediante el reenvio normativo), abstractas (conforme a los principios de jerarquia, competencia, subsidiariedad, y prevalencia y primacía) y horizontales (a través del Derecho comparado). Para concluir, se termina con unas consideraciones críticas en torno a cómo entender las relaciones entre ordenamientos jurídicos desde distintos niveles, como desde un entendimiento del Derecho en red.

ABSTRACT: This paper aims to study the relationships between legal systems in the context of globalization and from a constitutional perspective. It begins by presenting the changes that globalization caused in the understanding of law. Secondly, we study the different types of legal systems that can be identified, always under the capacity and systematic shaping of the Constitution. Then, we proceed to the analysis of the relationships between legal systems, starting with the idea of pluralism, then indicating several degrees of relationship between legal systems and finally classifying the legal relations between systems depending on specific relationships (by calling norms from other systems), abstract relationships (in accordance with the principles of hierarchy, competition, subsidiarity, and prevalence, primacy)

\footnotetext{
* Trabajo recibido el 29 de octubre de 2013 y aceptado el 6 de agosto de 2014.

** Doctor en Derecho (1999, Universidad de Granada), colaborador en el "Servizio Studi” de la Corte Constitucional italiana (2002), Profesor Titular de Universidad (Departamento de Derecho Constitucional, Universidad de Granada), y responsable del curso "Relaciones entre ordenamientos jurídicos en el contexto europeo" en el seno del Máster Oficial de la Universidad de Granada "Derecho constitucional europeo" (y que coordina Francisco Balaguer Callejón).
} 
and horizontal relationships (through comparative law). To conclude, the paper ends with some critical considerations about how to understand the relationships between legal systems at different levels, and how to understand a networked concept of law.

PALABRAS CLAVE: Constitución, globalización, Relaciones entre ordenamientos jurídicos, Pluralismo ordinamental, Reenvio, Jerarquí, Competencia, Subsidiariedad, Prevalencia, Primacía, Derecho comparado, Derecho en red.

KEY WORDS: Constitution, Globalization, Relationships between legal systems, Pluralism, The calling of another legal system, Hierarchy, Competence, Subsidiarity, Preemption, Primacy, Comparative law, Network law.

\section{INTRODUCCIÓN: DERECHO Y GLOBALIZACIÓN}

Desde hace tiempo buena parte de la atención de la doctrina constitucional gira, si no directamente, sí que al menos instrumentalmente en torno a las relaciones entre ordenamientos jurídicos. Y esto ya sea porque el estudio sobre las fuentes del Derecho en la actualidad requiere de ellas, al venir dichas fuentes a desplegarse en un marco de pluralidad ordinamental; porque el análisis de la ordenación territorial de los Estados descentralizados así lo supone; porque, y de manera contrapuesta ahora, el estudio de los procesos de integración supranacional asimismo da lugar a ello; porque el reconocimiento, alcance y garantía de los derechos fundamentales, en un plano constitucional, conecta con la expansión de los derechos humanos a nivel internacional; o porque, y simplemente, el Derecho constitucional hoy se desarrolla en un contexto globalizado, en el que se observa una constante interacción de normas jurídicas pertenecientes a distintos órdenes jurídicos ${ }^{1}$. Al hilo de esto último, precisamente, no se ha de olvidar la consideración del Derecho, en general, y del Derecho constitucional, en particular, como producto histórico; o lo que es lo mismo, la constatación de cómo el Derecho se expresa y se desarrolla en un tiempo, de manera que su estudio, aun desde una perspectiva sincrónica, requiere de su adecuada y previa contextualización temporal. Y consecuentemente que, al día de hoy, tal contextualización del Derecho constitucional nos lleve a la globalización, en cuanto que vigente proceso histórico de difuminación de fronteras y debilitación de los Estados y sus ordenamientos ${ }^{2}$.

1 Para una primera aproximación a la interacción entre ordenamientos jurídicos en la actualidad, y a modo de paradigma constitucional de una acepción cultural y cooperativa del Derecho, vid. ScHILLACI (2012a), pp. 329 y ss. Y por otra parte, sobre cómo habiendo existido siempre la interconexión de ordenamientos, en la actualidad ésta alcanza una nueva dimensión cualitativa, mutando, en razón a su extraordinaria intensidad, cfr. Martín-Retortillo Baquer (2004), pp. 20-21.

2 Ya, sobre la globalización y sus efectos (con carácter general, y desde diversas perspectivas), vid.: BECK (1998); Faria (2001); Denninger (2004); y Von Bogdandy (2004). 
Cabe así plantearnos la conexión entre globalización y Derecho, y a su luz (o sombras) interrogarnos por la globalización misma del Derecho y por su proyección sobre las relaciones entre ordenamientos; incluso, postular la aparición de un Derecho globalizado y/o un Derecho de la globalización. Sin embargo, no cabe hablar aún de una globalización del (un) Derecho en sentido abstracto, más allá de ciertas manifestaciones del mismo (como pueden ser los derechos humanos, y aunque parcial y limitadamente), por cuanto que todavía está lejos de apreciarse una determinada y definitiva universalización de éste. Lo que sí resulta posible plantearnos, no obstante, es cómo queda o resulta el Derecho bajo el influjo de la globalización: el Derecho globalizado 3 ; o mejor, el Derecho de la globalización, en cuanto que entendimiento del Derecho en el contexto de la globalización y al influjo de las transformaciones que ésta supone en aquél (nuevos sujetos productores de normas y titulares de derechos, nuevos espacios y ámbitos jurídicos -e incluso de tiempos-, nuevos tipos normativos con diversas densidades jurídicas -el soft law-, nuevas formas de realización y articulación del Derecho, nuevas maneras de entender las relaciones entre ordenamientos, etc. $)^{4}$. Y ello, además, a la vista del progreso tecnológico como motor y catalizador de la globalización (a la par que globalización y desarrollo tecnológico se retroalimentan), y la intensidad con que ella actúa ante la política, dando lugar a cierta capitulación democrática y jurídica en relación al modelo constitucional de Estado de Derecho y de Democracia históricamente alcanzado, y así respecto al propio concepto de Constitución normativa y al sistema jurídico desarrollado a su amparo ${ }^{5}$.

Es desde este complejo contexto que dedicamos las siguientes páginas a las relaciones entre ordenamientos jurídicos desde el Derecho constitucional; pero en el entendido de un Derecho constitucional más allá de la Constitución estatal, y en cuanto abierto a espacios en los que existe ejercicio de poder público y es susceptible (y necesario) de limitación mediante instrumentos constitucionales

3 CASSESE (2009).

4 Cfr. De Julios-Campuzano (2009); y Garrido Gómez (2010).

5 También de interés en relación a la globalización son las transformaciones que supone la consolidación y el desarrollo de ciertas economías emergentes, como China, India, Rusia o Brasil (las conocidas como BRIC), en el vigente contexto mundial, y consecuentemente la necesidad de tener en mente sus respectivos ordenamientos, con sus respectivas singularidades, ante el reto de un entendimiento global de las relaciones interordinamentales. Y ello por su propia masa crítica (mercado, población, territorio, poder y peso político internacional, cultura, etc.) a la hora de su interrelación con la globalización (de manera que ésta no se puede plantear igual que respecto a pequeños y medianos Estados, como acontece en la mayoría de los casos), como por su diverso grado (en algunos de dichos Estados) de disposición constitucional y democrática frente al estándar político y jurídico históricamente alcanzado. 
a fin de garantizar derechos y libertades ${ }^{6} . \mathrm{Y}$ a tales efectos, primeramente, que comencemos por las transformaciones que para el Derecho supone la globalización, para entrar en los distintos tipos de ordenamientos que cabe advertir; y esto, además, desde la capacidad conformadora y sistemática que aún supone la Constitución normativa respecto a los ordenamientos estatales; luego, ya, concretar en las relaciones de normas que pertenecen a diversos órdenes jurídicos; y para terminar, claro está, con unas consideraciones finales y críticas en torno a diversos modelos desde los que hoy cabe entablar dichas relaciones ${ }^{7}$.

\section{Tipos DE ORDENAMIENTOS JURÍDICOS}

Cuestión previa al análisis de las relaciones entre ordenamientos jurídicos es la naturaleza misma de los diversos ordenamientos, por cuanto aquéllas dependen de esto. A los efectos de estas páginas, destaca la distinción entre ordenamientos originarios y derivados, y dependientes e independientes ${ }^{8}$. Respecto a los primeros, se habla de ordenamientos jurídicos originarios cuando no encuentran fundamento u origen en otro ordenamiento previo, mientras que son derivados los que sí lo tienen; en cambio son independientes los ordenamientos cuya validez no obedece a otro, mientras que los dependientes sí lo son. En los independientes, a su vez, la validez de los mismos depende de su eficacia real; es decir, de su efectiva realización?.

Aunque a primera vista parecería coligarse la condición de dependencia de un ordenamiento de su carácter derivado, no es finalmente así, pues cabe que un ordenamiento inicialmente derivado de otro gane al tiempo autonomía de éste; es el caso, por ejemplo, del Derecho de la Unión Europea, a la vista de cómo aun naciendo de manera derivada respecto de los Derechos nacionales de los Estados miembros, ha terminado por reconocer autónomamente su independencia de

6 Para una primera aproximación a este entendimiento del Derecho Constitucional, vid.: BALAGUER CALLEJÓN (2012b), pp. 3045-3049, y Guillén López (2009).

7 Tal vez, y al hilo de cada uno de los tópicos a tratar en estas páginas, que no resulte ésta una investigación novedosa; y es que nuestro interés donde se centra es en la sistematización en sí de las relaciones entre ordenamientos (donde desarrollamos una sistematización propia), así como en el cuestionamiento de la capacidad normativo-constitucional al respecto.

8 Robles Morchón (2007), pp. 40-43. Por otra parte, asimismo cabe hablar, a partir de la relación entre ordenamiento jurídico y Estado, de ordenamientos supra-estatales, infra-estatales, colaterales (o para estatales), e incluso antiestatales: Modugno (1985), pp. 231 y ss.; y BobBIo (1991), p. 255.

9 Modugno (1985), pp. 80-84, y 224; Balaguer Callejón (1991a), pp. 93-95, y 97. 
éstos. En tal sentido, recuérdese cómo el Derecho comunitario europeo desde su origen se planteó al servicio de un mercado único y en busca de una identidad propia, y ello mediante su autoafirmación ante los Estados y los Derechos estatales, como del Derecho internacional y de las organizaciones nacidas a su amparo ${ }^{10}$. E igualmente cabría plantearse en relación a los ordenamientos originarios y su carácter independiente, pues también es posible que tales ordenamientos pierdan tal independencia (parcial o total) al pasar a reconocer autónomamente su sujeción a otros; es el caso ahora de los Derechos nacionales de los Estados miembros de la Unión Europea, por cuanto resultan finalmente limitados por el Derecho de la Unión, o los supuestos de incorporación (subsunción) de ordenamientos jurídicos en otros, como acontece en determinados procesos federativos (por ejemplo, el caso norteamericano en su conformación histórica).

Por otra parte, se ha de distinguir también entre ordenamientos jurídicos públicos y no públicos, en atención a su origen ${ }^{11}$. Si de acuerdo a la concepción institucionalista se abría ya la posibilidad de atribuir a instituciones no públicas la conformación de ordenamientos jurídicos, ciertamente que con la globalización se advierte una mayor incidencia de ordenamientos de origen privado en la esfera pública ${ }^{12}$, como acontece hoy en el mercado internacional a la luz de la lex mercatoria; y ello, además, asumiendo la capacidad de dichos ordenamientos privados para entrar en simbiosis con los ordenamientos públicos, llegando incluso a condicionarlos ${ }^{13}$. A su vez, dentro de los ordenamientos públicos destacan los articulados en torno a Constituciones normativas, dada la máxima pretensión y capacidad jurídica de éstas en la conformación racional de aquéllos.

\section{ORDENAMIENTO Y CONSTITUCIÓN NORMATIVA}

No obstante la referida proliferación de ordenamientos jurídicos no estatales en la actualidad, los Estados siguen siendo espacios públicos (políticos, jurídicos,

10 Así, precisamente, vendría a expresarlo el Tribunal de Justicia en dos históricas Sentencias: la Van Gend en Loos, de 5 de febrero de 1963, y la Costa/ENEL, de 15 de julio de 1964.

11 De "ordenamenti di formazione spotanea" cabría hablar, siguiendo a Modugno (1985), p. 221.

12 De "re-privatización de amplias zonas del planeta jurídico" nos habla Grossi (2010), p. 387. Y MuÑoz MACHADO insiste en el retraimiento de los poderes públicos, y la emergencia de la sociedad civil, en importantes materias, viniéndose a potenciar la autorregulación (2006), pp. 110-111.

13 Ya, Modugno (1985), pp. 222-223. Otra cosa es la situación asimétrica en la que se encuentran tales ordenamientos privados respecto a los públicos, y de ahí la importancia de su reconocimiento expreso o tácito por estos últimos para su efectiva consideración como auténticos ordenamientos jurídicos; RESCIGNO (2001), pp. 201-202. 
sociales y económicos) ineludibles en el actual contexto global, sin perjuicio de sus cambios y efectiva restricción; y al amparo de ello, que los ordenamientos jurídicos estatales continúen ocupando el protagonismo en las relaciones entre ordenamientos, sin perjuicio asimismo de la reconducción o delimitación de éstos al referido contexto global ${ }^{14}$. En tal sentido, y a su vez, se ha de advertir la preponderancia en buena parte de los Estados de su ordenación jurídica y política a partir de Constituciones, y al hilo de ello la configuración asimismo de sus respectivos ordenamientos jurídicos desde y por Constituciones. Y es que tales Constituciones, a través de sus respectivas normas sobre producción jurídica (así como de las sustantivas), estructuran los ordenamientos de los que son cúspide y base, además de dotarlos de unidad y coherencia. Y ello, de un lado (y desde una perspectiva clásica), en cuanto que las Constituciones se presentan como cúspide de sus respectivos ordenamientos dado que son parámetro de validez de todas las normas jurídicas que integran dichos ordenamientos; y a estos efectos, ejerciendo un papel esencial la jurisdicción (y en particular la jurisdicción constitucional, en sus diversas acepciones y modalidades), ya que agentes privilegiados de la sistematización del orden jurídico ${ }^{15}$. Pero también, y de otro lado, en cuanto que las Constituciones son raiz o base fundacional de sus respectivos ordenamientos pues proyectan cómo se han de desarrollar los mismos; y a estos efectos, ahora, desde el protagonismo de los poderes políticos con capacidad normativa, pues éstos han de ejercer sus potestades normativas conforme a lo indicado por la Constitución ${ }^{16}$.

Desde tal consideración, a su vez, y para el caso de ordenamientos estatales compuestos (Estados descentralizados, en sus diversas acepciones), que las Constituciones sigan desenvolviendo tal función de cierre y fundación, además de garantía última y básica de la unidad ordinamental total o global17; y es que las Constituciones normativas en tales supuestos son claves en la conformación plural de la ordenación territorial, política y jurídica de dichos Estados. Pero además, e incluso (y en un paso más), respecto al rol de las Constituciones normativas en relación a otros ordenamientos externos a los Estados, ya que éstas asimismo han asumido una función de apertura a dichos ordenamientos al actuar ellas como centro de imputación y ordenación de dichas relaciones ordinamentales ${ }^{18}$. No

14 Entre otros, CASSESE (2002).

15 Balaguer Callejón (2012a), pp. 43-45, 69-70 y 82-84.

16 Respectivamente: ZagrebelsKy (2012), pp. 69-70; у Dе Отто (1988), p. 83.

17 Balaguer Callejón (1991a), pp. 85-88, y (1992), pp. 135-137, y 184-186.

18 Balaguer Callejón (1991a), pp. 83-84. 
en vano, y respecto al Derecho internacional en general, mas también respecto a organizaciones regionales de integración en particular, cabe advertir normas constitucionales (cláusulas) específicamente determinadas a dirigir y conformar dichas relaciones, estableciendo los instrumentos y límites a tal apertura ${ }^{19}$. Otra cosa es cómo, finalmente, la recepción ahora de dicho Derecho externo en los ordenamientos estatales acabe por transformar, a nivel interno, los propios ordenamientos nacionales; y ello, todavía más, a la sombra de la globalización y de la proliferación de otros ordenamientos diversos que terminan por interactuar con los ordenamientos públicos-estatales e incidir en su interior. Al respecto, entonces, de lo que cabría hablar es de cierta crisis de la efectiva capacidad de las Constituciones normativas para determinar de manera íntegra, eficiente y adecuadamente sus respectivos ordenamientos jurídicos, pues éstos se desenvuelven en parte al margen de sus específicas previsiones constitucionales.

Con todo indicar que, en principio, la ordenación constitucional de las relaciones de los ordenamientos estatales con otros ordenamientos se plantean fundamentalmente (que no exclusivamente) y de manera endógena desde los propios sistemas constitucionales internos (según se ha adelantado), sin perjuicio de reconocer que tales relaciones a su vez sean definidas, en un plano dialéctico (y ulterior), desde los otros y externos ordenamientos jurídicos ${ }^{20}$; por tanto, de lo que se trata siempre (y conforme vamos a profundizar en el siguiente epígrafe) es de un doble eje en torno al cual giran las relaciones ordinamentales, de forma que las Constituciones estatales lo más que definen es uno de ellos, pero no el otro (en manos, claro está, del otro sistema normativo externo con el que entra en contacto el ordenamiento estatal). En tal sentido, precisamente, las normas constitucionales vienen a delimitar esta dimensión relativa que en todo ordenamiento jurídico independiente se da a la hora de entrar en contacto con otro, por cuanto que cada ordenamiento al relacionarse con un tercero tiende a delimitar tal relación desde su propia perspectiva ${ }^{21}$, sin perjuicio, claro está, de que dicho ordenamiento se abra más o menos a dicha relación según se acaba de apuntar; y así que la sistematización jurídica que supone la Constitución a nivel interno, fundamentada en la validez, no sea trasladable respecto a normas externas, pues

19 Como "Derecho constitucional internacional", Mirkine-Guetzévitch (2009). E igualmente cabría plantearse en relación a los procesos de integración supranacional: de "Derecho Constitucional Nacional sobre Europa”, por ejemplo, HäBERLE (1996), pp. 99-131; y a partir de cláusulas constitucionales al respecto, a modo de "cláusula general europea", CRUZ Villalón (2006).

20 Paulus (2013), pp. 93-94.

21 Robles Morchón (2007), pp. 45-47. 
la validez de éstas dependerá de su propio ordenamiento de referencia ${ }^{22}$. Otra cosa es, siempre, la potencialidad constitucional para determinar a nivel interno el grado de recepción del Derecho externo conforme al sistema de fuentes interno, de manera que éste no sólo opte por opciones más o menos abiertas respecto a la hora de establecer relaciones con Derecho externo (nuevamente), sino a su posible proyección o alcance, luego, a nivel interno, de acuerdo a las normas sobre producción jurídica atribuyendo un determinado valor jurídico concreto a normas externas recepcionadas dentro del propio sistema de fuentes del Derecho.

Para concluir este epígrafe se ha de reconocer, y más allá de la clásica identificación entre Constitución y Estado, la progresiva asunción y extensión del Derecho Constitucional en espacios jurídicos no estatales, y en especial a nivel internacional y de integración; y con ello, llegándose a afirmar la extensión del constitucionalismo más allá del Estado y de la propia Constitución ${ }^{23}$.

\section{Pluralidad y pluralismo ordinamental}

Aunque resulte una obviedad, el planteamiento de relaciones entre ordenamientos supone, de partida, el reconocimiento de una situación de pluralidad ordinamental; o lo que es igual, la existencia de dos o más ordenamientos jurídicos, con sus respectivas normas, interactuando ${ }^{24}$. Pero una cosa es el reconocimiento de una pluralidad ordinamental, y otra deducir automáticamente un valor jurídico y político concreto de esto, pues ello, en cuanto tal, sólo supone una mera realidad jurídico-normativa compartida, en la que, eso sí, un ordenamiento (fundamentalmente estatal) carece del monopolio de producción de las normas jurídicas. Y eso, a su vez, en relación a la distinción entre una mera realidad de pluralidad de ordenamientos, y la previsión ahora sí de un Derecho plural o compuesto, pues mientras lo primero únicamente es constatación fáctica de la existencia de una serie de centros productores de normas jurídicas (atiéndase a la Edad Media, por ejemplo)25, lo segundo, en cambio, sí que es expresión del reconocimiento y

22 Requejo Pagés (2006), en especial pp. 443-446. No obstante, está el problema del control de constitucionalidad de normas internas que traigan causa directa de otro ordenamiento externo, como sucede en relación a normas nacionales contrarias a una Constitución de un Estado miembro de la Unión cuando tal norma es desarrollo o consecuencia del Derecho europeo; al respecto de tal problema, vid. Alonso García (2006).

23 PACE (2004).

24 Cfr. Twining (2009), p. 28.

25 Grossi (2002). Sobre la pluralidad de ordenamientos como facticidad, cfr. Crisafulli (1970), p. 35. 
garantía jurídica de una pluralidad de centros detentadores de poder político y de producción de Derecho (pluralismo, ahora), según históricamente se ha significado desde el federalismo y se ha desarrollado a la vista de la consolidación del concepto contemporáneo de Constitución normativa (como expresión y garantía de la democracia y del pluralismo político, precisamente).

Ahora bien, lo anterior también conlleva consecuencias a los efectos de la ordenación de las relaciones entre ordenamientos, pues: ante la simple constatación plural de ordenamientos no hay regla única, ni monopolio en la determinación de las relaciones entre ordenamientos jurídicos, de forma que la respuesta tenderá a ser plural y vendrá desde los diversos sistemas afectados, entrando éstos en competencia por el control de la relación (en mayor o menor sentido); mientras que en el caso de un ordenamiento plural o compuesto, el mismo orden normativo total o superior que reconoce y garantiza tal pluralismo reconoce y garantiza a su vez la unidad, de modo que ordena y resuelve las relaciones y conflictos que surgen entre los ordenamientos existentes a su amparo ${ }^{26}$.

Así, en los Estados política y jurídicamente descentralizados la Constitución estatal es a la par soporte de tal descentralización ordinamental, al dar lugar o reconocer diversos ordenamientos territoriales, como de la garantía misma de la unidad del entero sistema normativo a nivel estatal-total ahora (según se ha mostrado más arriba); y ello, al conservar el control de la regulación de las relaciones entre los diversos ordenamientos a los que aquélla da lugar o reconoce. A estos efectos, la Constitución, directa o indirectamente, determina normativamente tanto las reglas de conformación y ordenación de la propia descentralización jurídica (y política), como las reglas de resolución de conflictos con las que garantizar la unidad y sistematicidad del entero orden normativo nacional. Mientras, y con relación al Derecho europeo y los Derechos internos de los Estados miembros de la actual Unión Europea, la falta de una auténtica Constitución europea al día de hoy, a modo de fundamento y garantía del plural sistema normativo resultante, impide todavía la anterior reconstrucción, de forma que la regulación de las relaciones entre los diversos ordenamientos no queda aún exclusivamente determinada por ninguno de ellos; y con esto, la falta de una total unidad del Derecho en Europa ${ }^{27}$.

\footnotetext{
26 Ya, Sánchez Barrilao (2004b), pp. 131-132.

$27 \mathrm{Al}$ contrario, tal ordenación continúa siendo el resultado de la comunicación de principios indicados y orientados desde los diversos ordenamientos, en pugna dialéctica: son la primacía del Derecho europeo y la supremacía constitucional (fundamentalmente), y sin llegar ninguno a dominar enteramente al otro; MENÉNDEZ (2007), pp. 141-146. Obviamente tal situación se habría de resolver, en dicho sentido, de mano de una verdadera Constitución en Europa, en cuanto fundamento y garantía, que no simple consecuencia,
} 
Con todo, se ha de reconocer situaciones intermedias, como la que en buena medida acontece realmente en el supuesto anterior, en las que la coexistencia plural de ordenamientos supone ya un pre-estadio fáctico de efectivo pluralismo ordinamental en cuanto que los diversos ordenamientos jurídicos reconozcan y garanticen por sí mismos cierta capacidad de interacción con otros; no en vano, cuando un ordenamiento expresamente prevé su relación con otro, o en un paso más, incluso, cierta limitación o sujeción ante ese otro ordenamiento, no se puede negar que el segundo ordenamiento es visto por el primero con un determinado valor positivo para su orden interno y por tanto promueve ya un pre-estadio de pluralismo ordinamental 28 .

Por último, se ha de advertir nuevamente la comunicabilidad ordinamental que supone la pluralidad de ordenamientos jurídicos en el contexto de la globalización, de manera que la apertura de unos ordenamientos a otros finalmente da lugar, más allá de relaciones entre los mismos, a recíprocas influencias (comunicándose), exportando e importando institutos y principios de unos a otros ${ }^{29}$; y con ello, al tiempo, originando respuestas comunes, compartidas, a cuestiones que se presentan de manera global, convergiendo así los Derechos constitucionales nacionales al respecto ${ }^{30}$.

\section{De LA COEXISTENCIA A LA COOPERACIÓN E INTEGRACIÓN ENTRE ORDENAMIENTOS. LA SUBSUNCIÓN, EL CONCURSO Y LA ANUENCIA DE ORDENAMIENTOS}

A la hora de analizar las relaciones entre ordenamientos jurídicos la doctrina distingue diversos grados de interacción respecto de su alcance, hablándose así de

del plural entramado ordinamental; y en este sentido, que el postulado de una Constitución material de la Unión Europea (en tanto que reconocimiento, por algunos, de una ordenación ya de la organización de la Unión y de las relaciones de su Derecho con el de los Estados miembros), no sea sino mera constatación de una realidad compleja, compuesta y plural, pero ajena de un auténtico pluralismo político y ordinamental reconducible a una unidad del Derecho en Europa. Otra cosa es la proyección constitucional de los Tratados constitutivos de la Unión Europea respecto al Derecho derivado de ésta y a su actuación, e incluso la consideración a tales efectos del Tribunal de Justicia como jurisdicción constitucional. Es más, se advierte el progresivo reconocimiento de elementos constitucionales en el Derecho de la Unión Europea, en particular en sus Tratados, ante la progresiva integración en aspectos cada vez más sensibles para las Constituciones de los Estados; cfr. SÁnchez Barrilao (2009), pp. 140-143, y (2012), pp. 85-93.

28 Y así cabría postularse en relación al Derecho europeo desde la percepción que del mismo reivindican ahora las modernas tesis del pluralismo constitucional en su conformación e integración. Es el caso de Maduro (2012), al presumir un vínculo dialéctico y recíproco entre el Derecho de la Unión y los distintos Derechos nacionales en una dinámica de cooperación y reconocimiento mutuos, sin perjuicio de situaciones de conflicto entre éstos, según Sarmiento (2012), pp. 287-291.

29 Pizzorusso (2009), en particular pp. 246-250.

30 Tushnet (2009); y conforme acontece hoy especialmente a nivel europeo, según CHITI (2010). 
relaciones de mera coexistencia, de cooperación y de integración ordinamental ${ }^{31}$. A esta distinción relacional cabría, además, añadir supuestos de auténtica subsunción de ordenamientos jurídicos, en tanto que uno (o unos) acaba(n) por incluirse en la extensión o comprensión de otro, así como de concurso ordinamental cuando varios ordenamientos ahora coinciden en una situación subsumida y paralela respecto a otro del que dependen. Otra cosa es la aquiescencia de un ordenamiento respecto a otro, de manera que éste se relaciona con el primero en tanto que consentido por él: anuencia.

En cuanto a las relaciones de mera coexistencia entre ordenamientos jurídicos, éstas se dan cuando de ordenamientos originarios e independientes se trata, y se plantean como grado mínimo relacional ante la necesidad de resolver situaciones de contacto básico y fáctico de éstos. Aquí los ordenamientos evidentemente se encuentran ante una situación de simple pluralidad, si bien aceptan, eso sí, un mayor o menor (incluso ínfimo) soporte de relación entre los mismos a fin de coexistir (subsistir) unos con otros y reducir el conflicto que supone el ineludible contacto entre ellos. Naturalmente, además, el carácter endógeno de las relaciones ordinamentales se plantea aquí de la manera más intensa, pues cada ordenamiento busca garantizar su propia perspectiva ante el otro. Muestras de esta forma de entender las relaciones entre ordenamientos jurídicos son, por ejemplo, tanto las originarias relaciones directas entre Derechos estatales, como a través del Derecho internacional público en su dimensión convencional más clásica.

También, y en un nivel meramente horizontal, cabe que los ordenamientos consientan en abrirse o simplemente apelen, más o menos espontáneamente, a otros ordenamientos a fin de satisfacer necesidades o conveniencias internas (tanto normativas como jurisdiccionales), o meramente reconocer, a la par que fiscalizar (en pos de un pretendido interés público más general), espacios sociales propios y característicos (deporte, tecnología, etc.): de anuencia cabría así hablar; y ello respecto a ordenamientos públicos, como privados, fundamentalmente (como por ejemplo acontece con ocasión del Derecho deportivo). Naturalmente en tales casos el control de los primeros (en particular, estatales) sobre cómo se articula su relación con los segundos se da también de la manera más expresa y amplia posible, sin perjuicio de llegar a plantearse influencias inversas como consecuencia del efectivo contacto entre ellos, como de esta forma acontece con ocasión de las llamadas normas técnicas, por ejemplo 32 .

31 Robles Morchón (2007).

32 Y es que la genérica remisión pública a estándares como "la mejor tecnología disponible" o el "estado de la técnica”, supone finalmente que parámetros inicial y meramente técnicos (tecnológicos) y privados (tanto 
Otra cosa ocurre cuando los ordenamientos deciden cooperar entre varios a fin de alcanzar una meta que por sí solos no pueden lograr (de relaciones de coordinación). Sin perjuicio de que se mantenga el referido carácter endógeno de las relaciones ordinamentales, se alcanza un salto cualitativo ante la apertura por los propios ordenamientos respecto al mantenimiento de relaciones e instrumentos permanentes de colaboración y cooperación con otros; y es que la meta común ordinamental que se procura, exige entonces de los ordenamientos estatales una mayor aceptación (aun condicionada) de interrelación ordinamental, llegándose incluso a conformar un ulterior ordenamiento a tal propósito, capaz además de limitarlos. Éste sería el caso del Derecho internacional público en su dimensión más institucional, ahora.

Y en cuanto a las relaciones de integración entre ordenamientos, se seguiría en la progresión del supuesto anterior, de manera que, ante la perspectiva de profundizar aún más en una meta común, se acepta una cuasi-subsunción ante un nuevo ordenamiento al servicio de tal meta; y ello, incluso, asumiendo que este ordenamiento jurídico, sus normas, penetre en los primeros como si fuera parte de los mismos y desplazando sus propias normas. Es decir, se acepta ahora por los ordenamientos originarios (e inicialmente plenamente independientes) una muy fuerte apertura ante otro ordenamiento jurídico, que llega a penetrarlos, limitarlos y condicionarlos incluso (de cierta subordinación cabría hablar), mas sin alcanzar a una subsunción ordinamental completa al permanecer éstos todavía en una situación de no dependencia total del tercero; y por tanto en una situación final dialéctica de relación recíproca entre unos y otro (aun en diverso grado, respecto a unos y otros), por cuanto que éste último establece intensas normas de relación mas sin llegar a monopolizar dicha relación. Sin duda, es el caso del proceso de integración en Europa ${ }^{33}$, en el que continúan enfrentándose los principios de primacía del Derecho europeo y el de supremacía de las Constituciones de los Estados miembros ${ }^{34}$. De menor intensidad, en cambio, pero en línea hacia una integración supranacional (pues a medio camino de la mera cooperación y el caso

por su origen, como por su sujeción voluntaria) terminen por penetrar a nivel jurídico-público general; en tal sentido, precisamente, de cláusula general de remisión (indirecta) nos habla TARRÉS VIVES (2003), pp. 180-184.

33 Más allá de diversas aproximaciones a la Unión Europea desde el federalismo, como: espacio garante de un orden colectivo, a la par que integración política sobre un territorio y una ciudadanía, según VoN Bogdandy (2000); u "orden federal" construido desde los Estados, en cuanto que abiertos y/o cooperativos, y al que dotan de legitimidad, según WAHL (2006).

34 Por ejemplo, Lebeck (2006). De cierta autosuficiencia "en su esencia” cabría hablar para los Derechos nacionales ante el europeo, sin perjuicio del carácter abierto de éstos ("estatalidad abierta"): HuBER (2013), p. 138. 
europeo), está el MERCOSUR, al resultar los ordenamientos nacionales limitados por el Derecho derivado de aquél, mas sin contar, a diferencia del Derecho europeo, de su efecto directo, y ostentar una primacía aún en construcción 35 ; y en un escalón superior, la Comunidad Andina de Naciones, por cuanto que, sujetos los Estados miembros a su Derecho originario y derivado, y gozando de primacía y efecto directo respecto a los Derechos estatales ${ }^{36}$, no alcanza el Derecho andino el grado efectivo de desarrollo, realización y penetración que ostenta el europeo ${ }^{37}$.

Respecto a los supuestos de auténtica subsunción de ordenamientos jurídicos (en tanto que uno -o unos- está incluido en la extensión o comprensión de otro), así como de concurso (cuando varios ordenamientos ahora coinciden en una situación subsumida y paralela respecto a otro del que dependen), las relaciones vienen entonces determinadas fundamentalmente por el ordenamiento jurídico del que se depende (el ordenamiento constitucional o total); aunque existen identidades ordinamentales diversas y autónomas (pluralismo ordinamental), un ordenamiento jurídico, superior a los demás, articula oportuna y adecuadamente las relaciones con los otros en garantía potencial y jurídica de la unidad y coherencia plena del conjunto. Este es el caso de los sistemas federales o regionales.

Por último, pero al amparo ahora del título jurídico sobre el que quepa pivotar la articulación jurídica de las relaciones entre ordenamientos, cabe distinguir (de manera paralela a la anterior presentación) entre relaciones específicas, abstractas y horizontales; a ello dedicamos el siguiente epígrafe.

\section{LA ARTICULACIÓN JURÍDICA DE LAS RELACIONES ENTRE ORDENAMIENTOS:} RELACIONES ESPECÍFICAS, ABSTRACTAS Y HORIZONTALES (PLANTEAMIENTO GENERAL)

Presentados diversos grados de relaciones entre ordenamientos (en atención a su alcance), quedaría ver cómo se articulan jurídicamente éstas; y ello, en especial, a fin de recomponer, de la manera más adecuada, la seguridad jurídica en el contexto de la globalización. A tales efectos la doctrina advierte la conveniencia de indagar en torno a la existencia de títulos jurídicos que conecten los diversos ordenamientos, por cuanto no cualquier contacto de un ordenamiento con otro plantea verdadera relevancia jurídica a fin de reconstruir dicha seguridad jurí-

35 Entre otros, vid.: Olivar Jiménez (2009); y Almeida (2009).

36 Cfr. Tremolada Álvarez (2007).

37 Por ejemplo, Vela Orbegozo (2007). Y en concreto, sobre el menor grado de efectividad del Derecho andino respecto a los Derechos nacionales (y por diversos motivos), frente al modelo europeo: QUINDIMIL López (2012), pp. 108 y 123; y Vigil Toledo (2012), pp. 218-219, y 234. 
dica; en este sentido, y siguiendo a Romano, se consideran aquellos títulos en virtud de los cuales un ordenamiento jurídico "puede condicionar la existencia, el contenido o la eficacia de otro ordenamiento" 38 . No obstante, y a la vista de la intensidad cuantitativa y cualitativa de las efectivas relaciones que entre ordenamientos jurídicos se da en el vigente contexto de la globalización (pues es ello lo que caracteriza hoy las relaciones jurídicas ante décadas pasadas), que debamos replantearnos el alcance y desarrollo de tales títulos jurídicos; e incluso, si no es oportuno analizar relaciones que sin título expreso y sin conllevar situaciones de dependencia o limitación ordinamental, generan efectivas e intensas puestas en contacto entre ordenamientos de los que resultan o se ponen de manifiesto condicionamientos y/o influencias entre ellos. Es así que consideremos oportuno una mayor generosidad en el análisis propuesto, frente a anteriores respuestas.

En cuanto a lo primero, a su vez, cabría distinguir entre títulos concretos, de un lado, dando lugar a relaciones específicas entre ordenamientos jurídicos; y títulos generales, de otro, con relaciones ordinamentales abstractas ahora. En virtud de títulos jurídicos concretos un ordenamiento jurídico apela a otro en relación a un determinado fin interno, de manera que la relación se configura fundamentalmente desde el ordenamiento apelante, sin perjuicio de reconocer (y respetar) la identidad y características del ordenamiento apelado; en este caso, obviamente, la articulación jurídica entre los distintos ordenamientos jurídicos viene casi en su totalidad prefigurada por el primer ordenamiento y su sistema de fuentes del Derecho. Mientras, en el segundo caso, al ser el título general, éste se limitaría a abrir, más o menos (y tanto formal, como sustantivamente), un ordenamiento jurídico a otro, de manera que la relación ordinamental se nos presenta originariamente de forma más abstracta y, por tanto, menos delimitada inicialmente; a estos efectos, se nos plantea entonces ver también bajo qué criterios o principios jurídicos se llevan a cabo tales relaciones entre ordenamientos (y cómo funcionan), pues éstos serán los que en última instancia nos permitan alcanzar cierta seguridad jurídica en dichas relaciones.

\section{RELACIONES ESPECÍFICAS: EL REENVÍO}

Conforme se ha adelantado, los ordenamientos pueden entrar en contacto con otros mediante títulos jurídicos concretos, de manera que uno apela unila-

38 Balaguer Callejón (1991a), p. 83. Y sobre la categoría de relevancia en Romano, vid. Fontanelli (2011), pp. 80-83. 
teralmente a una parte de otro al respecto de una necesidad o finalidad interna; y por tanto, que la relación que venga a establecerse sea concreta y específica en razón a la necesidad o finalidad causal de la relación, y así limitada a la parte del ordenamiento apelado que el apelante requiere. También, por ello, que dicha relación ordinamental quede esencialmente determinada y prefigurada unilateralmente desde el ordenamiento apelante (conforme a su sistema de fuentes del Derecho, pero también sustantivamente), si bien reconociendo y respetando la identidad y características del ordenamiento apelado ${ }^{39}$.

Casi todas las relaciones específicas se articulan mediante cláusulas concretas de reenvío (sin perjuicio de su carácter, más o menos, concreto o amplio), a través de las cuales un ordenamiento jurídico recurre a las normas que regulen una determinada materia en otro ordenamiento en cada momento; es de este modo que el reenvío suponga el reconocimiento de una relación ordinamental, al quedar cierta regulación jurídica en el seno de un ordenamiento expresamente sujeta, no a concretos contenidos normativos, sino a lo que establezca otro ordenamiento jurídico al tiempo ${ }^{40}$. De esta forma sucede en el ámbito del Derecho internacional privado, o cuando el Derecho público reenvía y se abre a normas procedentes del sector privado (por ejemplo, normas técnicas) ${ }^{41}$. En ambos casos, en principio, se advierte un mayor dominio de la relación ordinamental que se establece por parte del Derecho apelante y receptor (como se ha adelantado), en razón a su interna garantía de unidad y de sus propios principios configuradores ${ }^{42}$.

Todavía en el ámbito del reenvío estarían también aquellos casos en los que las Constituciones remiten expresamente a otros ordenamientos a fin de integrar o delimitar un contenido constitucional. Este sería el caso, por ejemplo: del artículo 10.2 de la Constitución española, en virtud del cual "[1]as normas relativas a los

39 Pues de lo contrario, no tendría sentido la referida apelación. Otra cosa es que quepa advertirse, asimismo, la posibilidad de que el ordenamiento jurídico apelado termine por influir en el primero.

40 En torno al reenvío, entre otros, Balaguer Callejón (1991a), pp. 173-174.

41 Sobre cómo el reenvío viene abriéndose, a la luz de la vigente pluralidad ordinamental, más allá del Derecho internacional privado, Pizzorusso (2005), pp. 11-12. Y en particular, sobre el reenvío (dinámico) a normas técnicas de origen privado, TARRÉs VIVES (2003), pp. 178-180.

42 Sin perjuicio de reconocer supuestos: en los que la dimensión global del Derecho acogido termina por imponerse fácticamente al receptor (Como cabría plantearse respecto a la incidencia de la International Air Transport Association -IATA- en la regulación del transporte aéreo a nivel nacional); o simplemente, la relación ordinamental expresada se integra a su vez en un marco plural y complejo de relaciones entre ordenamientos jurídicos, como así viene a suceder, finalmente, en el referido Derecho internacional privado al día de hoy y con carácter general. 
derechos fundamentales y a las libertades que la Constitución reconoce se interpretarán de conformidad con la Declaración Universal de Derechos Humanos y los tratados y acuerdos internacionales sobre las mismas materias ratificados por España"43; o del vigente artículo 135.3, in fine, de la asimismo Constitución española tras su reforma de 2011, y conforme al cual la deuda pública del conjunto de las Administraciones Públicas españolas en relación con el producto interior bruto del Estado no podrá superar "el valor de referencia establecido en el Tratado de Funcionamiento de la Unión Europea” ${ }^{4}$.

Supuesto similar en este ámbito de relaciones es el reconocimiento que desde la Unión Europea se da al Convenio Europeo para la protección de los Derecho Humanos, junto a las tradiciones constitucionales comunes a los Estados miembros (artículos 6.3 del Tratado de la Unión Europea y 52.3 y 53 de la Carta de los Derechos Fundamentales de la Unión Europea) ${ }^{45}$, mas sin haber aún ratificado dicho Convenio (cuando, y sin embargo, ello se encuentra expresamente previsto en artículo 6.2 del Tratado de la Unión Europea); y esto, incluso, antes de su expresa positivización (así, en artículo F.2 del Tratado de la Unión Europea conforme al Tratado de Maastricht) a la luz de la jurisprudencia del Tribunal de Justicia ${ }^{46}$, ante la dificultad en un primer momento de concretar judicialmente el estándar de protección que suponía la consideración de los derechos de la persona como principios generales del Derecho originario comunitario, en aquel momento ${ }^{47}$.

43 Aun cuando los Tratados relativos a derechos humanos pueden considerarse como contenidos predeterminados, no se ha de olvidar su ulterior desarrollo y evolución conforme a su interpretación por órganos específicos de garantía. Pero ello, se insiste, en tanto que mero parámetro de interpretación constitucional, y no como instrumento a nuevos derechos fundamentales en España a través de los derechos humanos (sin perjuicio, claro está, de su consiguiente influencia); por ejemplo, vid. ReQUEJo PAGÉS (2000-2001). Por otra parte, acerca de la reciente reforma constitucional mexicana en un sentido similar (2011), aun abriéndose finalmente a la constitucionalización de los derechos humanos (artículo $1 \%$ ), vid. Clavero (2013).

44 Y ahora, y a diferencia del supuesto anterior, a modo de auténtico parámetro constitucional de la capacidad española de deuda pública, a la vista de la constitucionalización de la conocida como regla de oro que se viene dando en Europa. Así, y de manera general y crítica, sobre la reforma constitucional del artículo 135, vid. SÁNCHEZ BARrilao (2013), en especial pp. 689-690.

$45 \mathrm{Y}$ ello en tanto que principios generales del Derecho originario de la Unión, a la par que criterio interpretativo de los derechos fundamentales de la Unión Europea. Entre otros, vid. ScHILlaCi (2012a), pp. 369-374.

46 Sentencias Nold, de 14 de mayo de 1974, y Hauer, de 13 de diciembre de 1979, entre otras.

47 Por ejemplo, Cámara Villar (2005), pp. 15-20; Muñoz Machado (2006), pp. 494-497. 
Asimismo con respecto al reenvío cabe considerar la supletoriedad, de acuerdo a la cual un ordenamiento jurídico remite a otro ordenamiento a fin de solventar heterónomamente lagunas del primero mediante normas del segundo, y una vez que éstas no caben ser resueltas autointegrativamente ${ }^{48}$. Este sería el caso, por ejemplo, del artículo 42.2.1 del vigente Estatuto de Autonomía de Andalucía (Ley Orgánica No 2/2007, de 19 de marzo), conforme al cual el Derecho estatal (español) tendrá carácter supletorio en el ámbito de competencias exclusivas de la Comunidad Autónoma de Andalucía ${ }^{49}$.

Por otra parte adviértase que siendo el reenvío un instrumento dirigido a los aplicadores del Derecho (en especial, los jueces), a fin de completar el régimen jurídico que cubre un supuesto de hecho, cabe que indirectamente alcance a los productores de normas ${ }^{50}$, como que, incluso se dirija directamente ahora a éstos últimos; este sería el caso, por ejemplo, de normas que autorizan diferidamente la reforma de otras del mismo ordenamiento en atención a la alteración o modificación futura de otras normas pertenecientes a ordenamientos distintos ${ }^{51}$.

Finalmente, y junto al reenvío, está la técnica de la mera presuposición de un ordenamiento jurídico por otro ${ }^{52}$, cuando la debida interpretación y aplicación

48 Cfr. Balaguer Callejón (1991b).

49 Y esto de manera paralela, pero diversa, a la cláusula constitucional por la que el Derecho estatal es supletorio para los distintos ordenamientos autonómicos (artículo 149.3, in fine, de la Constitucional española), por cuanto que en este caso la heterointegración de las lagunas que aparezcan en los Derechos autonómicos no resulta establecida por ellos mismos, sino por la Constitución; sobre la distinción entre la cláusula constitucional de supletoriedad del Derecho estatal en España, frente a aquellas equivalentes de origen estatutario, SÁNCHEZ BARRILAO (1998), pp. 288-289. Cuestión distinta es, también, la potencial articulación supletoria del Derecho estatal en relación a ordenamientos autonómicos en España para el caso de incumplimiento por las Comunidades Autónomas del debido desarrollo normativo del Derecho europeo, ante la genérica responsabilidad estatal frente a la Unión (artículo 93, in fine, de la Constitución española, ahora). Al respecto, cfr. la polémica Sentencia del Tribunal Constitucional español 195/1998, de 1 de octubre; y sobre ésta, SÁNCHEZ BARRILAo (2004a). Más recientemente, por último, Sentencia del Tribunal Constitucional español 135/2013, de 6 de junio (F.J. No 4.b), en un sentido expreso a lo referido antes.

50 Piénsese en cómo el legislador español a la hora de regular un derecho fundamental no sólo ha de estar a la Constitución, sino además a los tratados en materia de derechos humanos conforme al artículo 10.2 de la Constitución, en tanto que parámetro interpretativo de los derechos fundamentales efectivamente constitucionalizados en España. Entre otras, vid. Sentencia del Tribunal Constitucional español 36/1991, de 14 de febrero (F.J. No 5).

51 Así, entre otras, Ley española No 32/2003, de 3 de noviembre, General de Telecomunicaciones, en la que, tras la inmediata definición del conjunto de servicios que integran el denominado servicio universal en materia de telecomunicaciones (artículo 22.1), se autorizaba al Gobierno a revisar y ampliar dichos servicios "de conformidad con la normativa comunitaria" futura (artículo 37.2).

52 Martines (1997), p. 110. 
de normas jurídicas de este segundo necesariamente presume las de un primero (de reenvío tácito, no obstante, cabría hablar) ${ }^{53}$.

\section{RELACIONES ABSTRACTAS:}

LOS PRINCIPIOS DE JERARQUÍA, COMPETENCIA, SUBSIDIARIEDAD Y PREVALENCIA

En cuanto a las relaciones abstractas entre ordenamientos jurídicos ahora, nos referimos (y según se ha adelantado) a aquellas relaciones ordinamentales que giran en torno a títulos generales a través de los cuales un ordenamiento jurídico se abre a otro (u otros) en su conjunto (tanto a nivel formal, como sustantivo), viniendo así a resultar una relación dinámica y bilateral (o multilateral, en su caso) entre los mismos, y con una proyección a priori no acotable ${ }^{54}$. Ello, no obstante, no obvia que dicha apertura pueda ser condicionada, material y formalmente, por el ordenamiento de referencia (el que en principio se abre al otro), si bien la relación dinámica resultante vendrá a manifestarse al tiempo dialéctica (en mayor o menor grado, de acuerdo a los tipos de ordenamientos que se conecten). Es por esto que dichas relaciones ordinamentales se nos presenten entonces menos delimitadas inicialmente, y a estos efectos una mayor necesidad de inquirir criterios o principios jurídicos que permitan articular tales relaciones con cierto grado de seguridad jurídica. De este modo, el planteamiento de títulos jurídicos generales nos mueve a indagar en el interior de los propios ordenamientos jurídicos, en tanto que son ellos los que (de una u otra manera) se abren de manera abstracta a otros ordenamientos, a la par que, y desde el propio ordenamiento, articulan a nivel interno dicha relación finalmente; sin embargo, el hecho de que dichos títulos planteen de ordinario la articulación desde su propia perspectiva ordinamental, cuando la relación es siempre entre dos o más ordenamientos, nos lleva a que los títulos deban ser jurídicamente comprendidos, en última instancia, desde una visión plural, dinámica y dialéctica (no sólo unilateralmente), de forma que los principios, criterios e instrumentos que articulan las relaciones ordinamentales abstractas terminan por definirse y entenderse pluriordinamentalmente55.

53 De esta forma vendría a suceder, por ejemplo, cuando los poderes públicos instrumentan webs (en particular, aquéllas que están dirigidas a la administración on line), y a tales efectos asumen la ordenación privada de los dominios de internet ante la regulación que de éstos realiza la Internet Corporation for Assigned Names and Numbers (ICANN).

54 "Por cláusula general, en el sentido más técnico de la expresión (Generalklausel), se entiende un precepto o categoría jurídica de potencialidad no previamente acotable”; CruZ VilLalón (2006), p. 52.

55 Aunque a nivel interno de un ordenamiento jurídico, claro está, éstos tiendan a desenvolverse conforme a lo establecido por éste, de manera que, finalmente, quepan diversas proyecciones o realizaciones de 
A tales efectos entendemos posible presentar diversos principios que, sin perjuicio de estar llamados originariamente a articular ordenamientos a nivel interno ${ }^{56}$, permiten potencialmente proyectarse entre ordenamientos; y ello, en unos casos, tendiendo a la estructuración de dichas relaciones ordinamentales, y en otros limitándose a resolver o acoplar jurisdiccionalmente éstas ${ }^{57}$. Adviértase, además, como tales principios no actúan de ordinario de manera exclusiva, de forma que concurren unos con otros, según el caso, dado el contexto pluriordinamental y complejo que supone la globalización ${ }^{58}$.

Respecto a los principios y criterios que pueden estructurar las relaciones entre ordenamientos, entendemos aquéllos que actúan como soporte de dichas relaciones; es decir, permiten a los sujetos normativos (principalmente políticos) articular adecuada y válidamente la producción de normas jurídicas que van a (o pueden) relacionarse con otras pertenecientes a diversos ordenamientos jurídicos. De este modo, su adecuado desenvolvimiento por dichos sujetos normativos garantizaría, de por sí, una cumplida articulación de tales relaciones ordinamentales, en cuanto que inhibiría ulteriores conflictos al respecto; e inversamente que su infracción, ahora, provoque conflictos y por tanto, y a la postre, permitan también ser tenidos en cuenta, en principio, como instrumentos o guías con los que resolver tales conflictos por parte de los aplicadores jurídicos, y especialmente por los órganos jurisdiccionales ${ }^{59}$.

dichos principios, criterios e instrumentos según la perspectiva concreta con la que éstos son efectivamente articulados según los respectivos ordenamientos. Muestra de ello es, por ejemplo, la Declaración 1/2004, de 13 de diciembre, del Tribunal Constitucional español acerca de la existencia o inexistencia de contradicción entre la Constitución española y los artículos I-6, II-111 y II-112 del Tratado por el que se establece una Constitución para Europa (de 29 de octubre de 2004), y en la que el alto Tribunal vendría a equiparar la primacía del Derecho europeo con la categoría prevalencia, más propia del Derecho constitucional español (F.J. No 4); entre otros, Sánchez Barrilao (2004b), pp. 144-146.

56 Si bien, claro está, la proyección, funcionamiento y entendimiento de tales principios y/o criterios en uno y otro caso varían (según que intra o interordinamental), dado que se alteran los presupuestos y realidades históricas y políticas sobre los que inicialmente se configuraron jurídicamente (intraordinamentalmente). Además, cabe que las normas que entran en relación con otras de distintos ordenamientos lo hacen a su vez en el seno de sus respectivos ordenamientos, los cuales se estructuran mediante tales principios, dificultando aún más su adecuada comprensión.

57 Sin perjuicio, no obstante, de que algunos de tales principios posean esa doble condición, u ostentando alguna puedan sin embargo potenciar, de manera refleja, el otro rol paralelamente.

58 Como acontece en España, pues el Derecho europeo entra en contacto con el español en tanto que ordenamiento compuesto, dado el Estado autonómico aquí.

59 De ahí que, de ordinario, cuando dichos principios son utilizados por los aplicadores del Derecho, en particular los jueces, supongan juicios sobre validez de normas en cuya producción aquéllos no se han visto respetados por los sujetos normativos. 
Los dos primeros criterios o principios a referir son los de jerarquía y competencia, si bien el primero con bastantes salvedades; y es que la jerarquía, recuérdese, es un principio que nace y se desarrolla entre fuentes del Derecho (intra ordenamiento), y en particular entre la ley y el reglamento (en el S. XIX, con el Estado liberal) ${ }^{60}$, de manera que, y al margen incluso de concepciones amplias sobre la jerarquía ${ }^{61}$, difícilmente cabe articularla respecto a relaciones entre ordenamien$\operatorname{tos}^{62}$. Otra cosa es si en vez de jerarquía hablamos de superioridad o dominio de un ordenamiento jurídico respecto a otro, y ello en relación a un ordenamiento subsumido en otro principal del que depende, como sucede en el caso de sistemas territorialmente descentralizados ${ }^{63}$.

Por otra parte, y desde el monismo kelseniano y en relación a los ordenamientos estatales y el internacional, cabría hablar de un primado de éste en cuanto a los primeros $^{64}$. Sin embargo, la consideración del aún referido carácter independiente y originario de aquéllos impediría tal consideración finalmente, a salvo de que el propio ordenamiento estatal expresamente se sujete, sometiéndose, al Derecho internacional ${ }^{65}$ : pero ello, entonces, y dado que usualmente a través de normas constitucionales, el problema se integraría a nivel de específico parámetro de constitucionalidad (por ejemplo, artículo 410.II de la Constitución de Bolivia) ${ }^{66}$;

60 Cfr. Balaguer Callejón (1991a), pp. 104-109 y 143-145.

61 En tal sentido, Requena López (2004).

62 A no ser que nos refiramos a la posición en la que quepa considerarse una norma foránea a un ordenamiento, pero integrada en el mismo a partir de una fuente reconocida o equiparada en éste y respecto a otras de él, de menor rango. Pensemos, por ejemplo, en la relación entre el Derecho internacional y el Derecho español, pero de manera específica respecto a una norma incorporada al ordenamiento español mediante un tratado internacional (artículo 96 Constitución) y en cuanto a normas meramente reglamentarias y sujetas al principio de legalidad (artículos 9.3, 97 y 106.1 Constitución), al poder considerar la referida norma internacional como parte de dicha legalidad.

63 Como acontece en España en relación a los ordenamientos jurídicos autonómicos, y al propiamente estatal, respecto al constitucional. De supremacía, que no de estricta jerarquía, cabe hablar respecto a la Constitución, y para el caso de un ordenamiento compuesto y plural (como es el español), en relación a cualquier norma jurídica subsumida en éste; en tal sentido, vid. BALAGUER CALLEJÓN (1992), p. 184. En cuanto a la idea de superioridad o dominio, de un lado, y subordinación, de otro, Modugno (1985), pp. 218-220.

64 De manera crítica sobre tal construcción kelseniana, a la vista del pluralismo ordinamental, SCHILLACI (2012a), pp. 196-199.

65 Crisafulli (1970), pp. 67-68.

66 Sobre tal precepto, vid.: Andaluz (2010), pp. 23-28; y Medinaceli Rojas (2012), pp. 143-149. Y sobre la distinción entre el control de convencionalidad y de constitucionalidad con ocasión de una autolimitación constitucional en relación al Derecho internacional, vid. Nogueira Alcala (2013a). 
o en un paso más allá, de limitación misma del poder de reforma constitucional (como acontece con la Constitución suiza, en su artículo 193.4)67. Otra cosa es la restricción que para un Derecho nacional puede llegar a suponer el Derecho internacional, especialmente en supuestos de relaciones de colaboración y cooperación (en particular, en materia de derechos humanos) ${ }^{68}$; y asimismo, el juicio de legitimidad que sobre tales relaciones quepa plantear según que éste se desarrolle desde el marco jurídico-jurisdiccional nacional o desde el internacional, y por tanto cómo la validez de la relación desde la perspectiva internacional no conlleva necesariamente su adecuación jurídica a nivel interno (y viceversa) ${ }^{69}$.

E igualmente todavía, y en última instancia, cabe plantear respecto al Derecho de la Unión Europea y el Derecho de los Estados miembros, por cuanto que, sin perjuicio del muy elevado grado de integración ordinamental alcanzado, la validez de los Derechos internos no depende todavía del Derecho europeo a pesar del alto desarrollo de los principios de primacía del segundo sobre los primeros $^{70}$, como del de interpretación conforme también de aquéllos en relación a éste; y ello, especialmente, cuando están en juego las clásicas libertades económico-comunitarias y la garantía de la unidad de mercado, al primar ambos sustantiva y funcionalmente no ya sobre los Derechos nacionales, sino sobre los propios derechos fundamentales ${ }^{71}$. Otra cosa es, nuevamente, que el Derecho europeo sea previsto expresamente como parámetro de constitucionalidad en un Derecho interno ${ }^{72}$; o que hoy el propio poder de reforma constitucional a

67 Vid. Koller y Biagnni (2002-2003), p. 624.

68 Por ejemplo, en el ámbito iberoamericano, vid. SAGỨs (2010).

$69 \mathrm{Y}$ desde esta consideración, la distinción entre el juicio de constitucionalidad de una norma internacional, de un lado (y a nivel interno), y el de validez de la misma en atención al propio Derecho internacional, de otro (y a nivel internacional, ahora). A tales efectos, por ejemplo, vid.: para el caso español, ReQuejo PAgÉs (1992), pp. 50-55; o para el chileno, Núñez Poblete (2010). En tal sentido, y para el supuesto español (nuevamente), resulta especialmente interesante la Sentencia del Tribunal Constitucional 155/2005, de 9 de junio, en la que se declara parcialmente inconstitucional la Ley No 13/1999, de 21 de abril, de adhesión de España a diversos Acuerdos del Fondo Monetario Internacional (y que trae causa del Decreto-Ley No 14/1998, de 9 de octubre, de adhesión de España a diversos Acuerdos del Fondo Monetario Internacional), mas sin que tal declaración lleve aparejada su nulidad (FJ No 10).

70 Llegando el Tribunal de Justicia a establecer cierta relación al respecto, con ocasión de la relevante Sentencia Simmenthal II, asunto 106/77, de 9 de marzo de 1978. De "preclusión", al respecto, nos habla Rodríguez-IzQuierdo Serrano (2011), pp. 114-116.

71 Sobre tal primacía, cfr. Mercado Pacheco (2012).

72 Como sucede con ocasión del vigente artículo 135.3, in fine, de la Constitución española, según se ha comentado. Vid. García-Andrade Gómez (2012), pp. 60-63. 
nivel estatal se vea limitado por el proceso de integración europea ${ }^{73}$. No en vano, finalmente, las relaciones entre el Derecho europeo y los Derechos estatales (constitucionales) continúan en una relación dialéctica de respectiva garantía, como demuestra el expreso condicionamiento ahora del mismo Derecho europeo al Derecho constitucional de los Estados europeos miembros de la Unión ${ }^{74}$. Y así, con todo, que el Derecho de la Unión Europea aún hoy resulte incapaz, por sí sólo, de conformar la unidad del Derecho europeo en relación al Derecho de los Estados miembros, si bien ambos terminan por complementarse en cuanto que Derechos parciales 75 .

$\mathrm{Al}$ respecto de esta última línea, el principio de competencia (y aun integrándose asimismo al interno de ordenamientos jurídicos) se proyecta mejor que el anterior (jerarquía) sobre las relaciones entre ordenamientos al suponer ahora el reconocimiento de una pluralidad de centros productores de normas; y por tanto, el reconocimiento de poderes normativos a unos sobre ciertas materias o ámbitos, mientras, e inversamente, se desapodera a otros al respecto. De ahí, precisamente, su impulso a la luz del constitucionalismo contemporáneo, dado el reconocimiento y garantía del pluralismo en el seno del Estado constitucional democrático de Derecho ${ }^{76}$. De otra parte, y al igual que sucede con el principio de jerarquía (pero como superioridad, y conforme a las salvedades señaladas más arriba), la competencia es un principio estructurador de relaciones entre ordenamientos, como de resolución de conflictos normativos (relativos a diversos ordenamientos) en su caso, de forma que está dirigido tanto a sujetos productores de normas, como a aplicadores jurídicos que han de resolver dichos conflictos; y a su vez que su quebranto por los sujetos productores de normas, verificado por órganos jurisdiccionales en resolución de un conflicto, suponga (en principio) la

73 Balaguer Callejón (2008a), en especial pp. 41 y ss. Asimismo, vid. Tapia Valdés (2008).

$74 \mathrm{Y}$ a modo de codificación europea de los tradicionales contralímites que determinados ordenamientos constitucionales nacionales habían venido advirtiendo ante el Derecho de la Unión: respeto a la identidad nacional, las estructuras fundamentales políticas y constitucionales de aquéllos, así como su autonomía local y regional (artículo 4.1 Tratado de la Unión Europea), con VeCCHIO (2012a); y la expresa consideración de las tradiciones constitucionales comunes a los Estados miembros en materia de derechos fundamentales, en cuanto que principios generales del Derecho europeo (artículos 6.3 Tratado de la Unión Europea, y 52.4 y 53 Carta de los Derechos Fundamentales de la Unión Europea), con SchillaCi ahora (2012b).

75 Según HÄBerle (2004), de pluralismo constitucional (en su dimensión ordinamental) a nivel europeo se llega a hablar, entonces; e incluso de equiordenación, en tanto que límites, solapamientos y concordancias entre los diversos ordenamientos que finalmente integran el Derecho europeo. PAULUS (2013), pp. 95-99, y 106.

76 Balaguer Callejón (1991a), pp. 148-149. 
falta de validez de la norma ilegítimamente producida ${ }^{77}$. En cuanto a las relaciones ordinamentales que el principio de competencia está llamado a regir, éstas son las propias entre ordenamientos jurídicos que concursan en situación de subsunción de otro del que dependen conjuntamente, de forma que en este último se determina qué ordenamiento de los primeros es el competente (y de ahí su carácter indirecto); así, y nuevamente, es el caso de ordenamientos jurídicos compuestos principalmente de tipo territorial (particularmente, los desarrollados en el S. $\mathrm{XX}$ ), pero también de carácter diverso como acontece (más recientemente) en el supuesto del reconocimiento y garantía constitucional de ordenamientos propios de colectivos o grupos humanos (los Derechos de los pueblos indígenas) ${ }^{78}$.

Respecto a situaciones de relaciones de mera integración ordinamental se ha de estar a su concreta proyección y desenvolvimiento, de manera que en relación a la Unión Europea, y dado que máximo exponente de la evolución e integración alcanzada, se ha de advertir una compleja situación. Originariamente y por tiempo, la genérica fórmula de atribución de facultades públicas por los Estados a favor de las Comunidades Europeas (luego, Comunidad Europea) en pos de fines y metas comunitarias, vino a establecer un abierto y dinámico instrumento en virtud del cual aquéllas pasaban a ejercer funciones normativas inicialmente estatales, bajo la aquiescencia, eso sí, de los propios Estados (según Tratados, como en relación a la intervención de éstos en el Consejo) ${ }^{79}$; y ello, a la par que el Tribunal de Justicia decantaba un principio conforme al cual los Derechos estatales resultaban desplazados en su aplicación por el Derecho comunitario (principio de primacía, según se ha adelantado y luego vamos a volver). Consecuencia de lo anterior sería que, al margen de algún intento jurisprudencial comunitario a fin de que tal primacía alcanzara negativamente la propia legitimidad de los Derechos nacionales ${ }^{80}$, no cupiera verdaderamente hablar de competencia en el sentido presentado más arriba, pues: sin perjuicio de que competencia y primacía (prevalencia) sean principios diversos e inicialmente incompatibles, los Estados realmente no terminaban de

\footnotetext{
77 Balaguer Callejón (1991a), pp. 107-109 y 148-150.

78 Desde tal perspectiva, artículos 2o, 11.3, 26.II.4, 30, 31, 42.II, 98.II, 119.I, 179.I y II, 190-192, 210, 211, 269, 270, 289-286, 303, 304, 374.II, 388, 394.III, 403 y 410.II de la Constitución de Bolivia (2009); y en relación al principio de competencia como articulador entre el Derecho estatal y el indígena allí, vid. Andaluz (2010), pp. 37-41.

79 Entre otros, acerca del principio de atribución y su ulterior articulación expansivo/funcional a favor de la Comunidad, cfr. Alonso García (1994), Capítulo VII.

80 La referida Sentencia del Tribunal de Justicia Simmenthal II, pero limitada al tiempo a que los Estados miembros no aprobaran Derecho interno contrario al comunitario.
} 
perder potestad normativa sobre los espacios comunitarios, si bien debiéndola adecuar al Derecho comunitario en razón, no tanto al desplazamiento final del Derecho estatal ante la primacía comunitaria, sino a la progresiva articulación de exigencia de responsabilidad a los Estados infractores al respecto.

Ciertamente la cuestión viene a cambiar cuando con el Tratado de Maastricht (ya Unión Europea) los Estados, buscando una mayor garantía de su propio espacio normativo (ante la progresiva ampliación implícita de los poderes comunitarios que se había vivido con anterioridad en atención funcional a la unidad del mercado), comienzan a postular una mayor delimitación de la atribución europea $^{81}$, llegando así, al tiempo, al sistema vigente establecido en el Tratado de Lisboa, el cual (y bajo el antecedente del modelo previsto por el nonato Tratado por el que se establece una Constitución para Europa, Parte I, Título III), sí habla ya de competencias exclusivas de la Unión, y en el sentido de desautorizar a los Estados miembros al respecto (artículo $3^{\circ}$ del Tratado de Funcionamiento de la Unión Europea), a la par que confina el alcance de los objetivos de la Unión. Con todo, y al margen del grado de exclusión efectiva que tal sistema supone para los Estados ${ }^{82}$, lo cierto es que el quebranto por los Estados de esta trasferencia competencial no supone todavía y de por sí problema de validez del Derecho estatal a nivel europeo, por cuanto que la Unión Europea carece de instrumentos jurídicos directos a fin de hacerla valer, más allá aún, claro está, de: la primacía del Derecho europeo, y de su instrumentación mediante la cuestión prejudicial (artículo 267 del Tratado de Funcionamiento de la Unión Europea); la exigencia de responsabilidad a los Estados infractores al respecto, mediante la acción por incumplimiento (artículos 258-260 del Tratado de Funcionamiento de la Unión Europea, ahora); y el principio de lealtad estatal a la Unión (artículo 4.3, in fine, del Tratado de la Unión Europea). La razón, nuevamente, estaría en la falta de un orden normativo unitario (mas sin tener que ser único) ${ }^{83}$ que permita una ordenación superior y efectiva de las relaciones entre los ordenamientos estatales y el estrictamente europeo (en particular, en su dicción derivada), según se viene comentando, a la par que la flexibilidad (elasticidad) que en última instancia ha

81 Vid.: Martín Y Pérez De Nanclares (2002); y Linde Paniagua (2002).

82 Pues no es total, ya que, además de poder estar los Estados facultados por la Unión y en relación a la aplicación del Derecho europeo, conforme al artículo 2.1 Tratado de Funcionamiento de la Unión Europea, dicho marco resulta exclusivo sólo respecto a la potestad normativa y en tanto que la Unión la haya efectivamente ejercido; de ahí que se ponga en duda tal categoría competencial.

83 De un hipotético "bloque europeo de la constitucionalidad", e incluso de "metaconstitucionalidad recíproca”, nos habla CruZ Villalón (2004), pp. 71 y ss., y 131 y ss. 
caracterizado (y sigue caracterizando) todo el sistema jurídico europeo y, consecuentemente, su orden competencial. Otra cosa es que: de un lado, el principio de competencia sí opere al interno del ordenamiento de la Unión Europea en tanto que parámetro de validez del Derecho europeo derivado por parte del propio Tribunal de Justicia de la Unión Europea (mediante el recurso de anulación, la cuestión prejudicial de validez y la excepción de ilegalidad); y de otro, y a nivel de los Estados, sí quepa hablar de quebranto constitucional interno cuando un Estado viola el marco competencial europeo ${ }^{84}$.

No obstante lo anterior se ha de advertir como, paradójicamente, el marco competencial de la Unión Europea, y así el principio de competencia, está siendo de facto más instrumentalizado por los Estados miembros que por la propia Unión Europea (en particular, respecto el Tribunal de Justicia), al haber advertido algunos Tribunales Constitucionales nacionales su condición de guardianes de los poderes estatales no cedidos a la Unión conforme a los Tratados y sus reformas, y la atribución competencial reconocida finalmente a ésta: se trata del principio o doctrina de la Kompetenz-Kompetenz $z^{85}$.

Todavía al hilo de la competencia, téngase en cuenta cómo instrumentos jurídicos no estrictamente normativos (o de normatividad relajada, pero con cierta autoridad jurídica: el soft law) de la Unión Europea, y dictados en ámbitos de mera cooperación (y por tanto, más allá del referido marco competencial), pueden finalmente adquirir juridicidad fuerte ante los Estados al exigírseles responsabilidad por no seguir su guía ${ }^{86}$; y de esta forma, que la Unión Europea haya recurrido a dichos instrumentos (de soft law) en casos en los que su competencia resultaba más que dudosa ${ }^{87}$.

Siguiente principio es el de subsidiariedad, el cual, aun de remotos antecedentes y amplia ambivalencia ${ }^{88}$, vive un importante impulso y desarrollo a la

84 Balaguer Callejón (2009), p. 94. Mas, sin perjuicio de que tal inconstitucionalidad no tenga que dar lugar a un juicio de validez interna dadas las dificultades de su materialización (pues la norma nacional puede ser aplicable en otros supuestos) y la más fácil implementación del principio de primacía del Derecho europeo al respecto.

85 Al respecto del caso alemán, Mahlmann (2010); y Aláez Corral (2012). Y así que un parámetro de validez que debería quedar bajo el monopolio jurisdiccional de la Unión (las competencias europeas) sea blandido por los Estados, lo cual, entendemos, no es sino consecuencia del referido carácter dinámico y dialéctico de cómo se relacionan efectivamente los ordenamientos.

86 Asunto Grimaldi, en Sentencia del Tribunal de Justicia de 13 de diciembre de 1989.

87 Alonso García (2001), en especial p. 75.

88 Respectivamente, vid.: Ridola (2001), pp. 210-213; y DonATi (2009), pp. 211-216. 
sombra de la globalización ${ }^{89}$; y decimos que en conexión con la competencia, pues la subsidiariedad también participa en la determinación del ejercicio de la potestad normativa ${ }^{90}$, sin perjuicio de su especificación como principio ante ésta ${ }^{91}$, en particular a la vista de las diversas formas en las que la subsidiariedad se declina y expresa en Derecho comparado ${ }^{92}$. Al respecto, la subsidiariedad actúa en supuestos de contacto de un ordenamiento con otro más general, instando a que las decisiones (en nuestro caso, las de tipo normativa) sobre determinadas materias o cuestiones sean adoptadas por determinados sujetos o entes (ordenamientos) frente a otros, a modo de cláusula de limitación de intervención ${ }^{93}$. Ello otorga a la subsidiariedad un importante calado político al momento de estructurar la producción normativa (en relación a sujetos productores de normas), mientras ve reducido, al tiempo, su ulterior operatividad resolutiva de conflictos ante órganos jurisdiccionales y su posterior control ${ }^{94}$.

A los anteriores efectos, la subsidiariedad se articula en torno a un doble eje, según que: de un lado, se busque acercar la decisión a aquéllos sobre los que ésta vaya luego a recaer (dimensión democrática de la subsidiariedad), o bien se opte por que la decisión la lleve a cabo quien mejor se encuentra llamado a decidir según la materia (dimensión eficiente y/o funcional de la subsidiariedad); y de otro, según que la subsidiariedad se plantee entre diversas entidades territoriales conforme su extensión y situación de superposición (subsidiariedad vertical), o se refiera entre los poderes públicos y la sociedad civil, o grupos sociales, abonando a favor de éstos un espacio y una capacidad normativa propia frente a los primeros (subsidiariedad horizontal) ${ }^{95}$. Al hilo de ello, y de su flexibilidad, es que la subsidiariedad se expanda (conforme se ha adelantado más arriba) en el contexto

89 TAPIA VAldÉs (2003), pp. 99-111.

90 De "modulación del ejercicio de la competencia" habla Balaguer Callejón (2003), pp. 16-19.

91 Pues la subsidiariedad no permite un criterio formal y abstracto de atribución de la competencia, al depender de casos concretos y en contextos determinados; Bin (2002), p. 156.

92 D’Atena (2010). También, vid. el trabajo colectivo de Derecho comparado que sobre los Estados descentralizados dirigen Argullol I Murgadas y Velasco Rico (2011).

93 Ridola (2001), p. 221.

94 Desde tal perspectiva, parece moverse Rodríguez-IzQUIERDo SERRANo en relación al Derecho europeo y la subsidiariedad al entenderla, junto a la primacía (y sin perjuicio de su evidente conexión con el de competencia) como principio constitucional en el federalismo europeo: (2011), pp. 67 y ss.

95 Tal vez, por esta razón, que no resulte manifiestamente evidente la dimensión de relación interordinamental de la subsidiariedad al perder operatividad con ocasión de conflictos normativos interordinamentales ante aplicadores del Derecho (los jueces); pero esto, sin perjuicio de que la subsidiariedad actúe como criterio 
complejo y contradictorio que supone la globalización: ya potenciando aproximar, avalando, a las entidades territoriales menores (ordenamientos locales) las decisiones que resulten más cercanas a los ciudadanos (por ejemplo, autonomía local); o ya porque, e inversamente, las decisiones se lleven a espacios superiores (más generales) cuando de cuestiones referidas a aspectos supraterritoriales se trate y sobre éstas se manifiestan mejor llamadas a decidir (medio ambiente).

En tal perspectiva, precisamente, encaja el entendimiento que de la subsidiaridad se plantea en la Unión Europea en relación a la materialización por la Unión de la efectiva asunción de las competencias compartidas (artículos 2.2 y $4^{\circ}$ del Tratado de Funcionamiento de la Unión Europea), de acuerdo al Protocolo No 2 sobre la aplicación de los principios de subsidiariedad y de proporcionalidad ${ }^{96}$, en tanto que instrumento de control político por los parlamentos nacionales (y regionales) de tal asunción, a la par que cauce democratizador de ella y del ulterior Derecho europeo derivado que se apruebe ${ }^{97}$.

También cabe hablar de expansión de la subsidiariedad como criterio relacional entre lo público y lo no público, buscando promover y garantizar (mas sin reservar, como sí sucede con la competencia) ${ }^{98}$ ciertos ámbitos normativos a favor del segundo, y fomentando así heterogéneos procesos de autorregulación'99.

estructurador al respecto y en relación a los productores de las normas. Ridola (2010), pp. 361 y ss.; también, de interés, Balaguer Callejón (2008b), pp. 148-150.

96 Por ejemplo, Martín Y Pérez De Nanclares (2008).

97 Con todo, adviértase que la subsidiariedad en este ámbito europeo, aun actuando como instrumento del ejercicio por la Unión de las competencias compartidas (nuevamente artículo 2.2 del Tratado de Funcionamiento de la Unión Europea), se despliega precisamente en dicho marco de competencias compartidas (artículo $4^{\circ}$ del Tratado de Funcionamiento de la Unión Europea), de manera que el principio de competencia delimita previamente, a su vez, la actuación del de subsidiariedad; RoDRíGUEz-IzQUIERDO SERRANO (2011), pp. 245-246.

98 Por cuanto que los poderes públicos se verán legitimados a intervenir en tanto que los particulares se muestren incapaces para proveer adecuadamente la satisfacción de sus propios intereses, y éstos tengan cierta proyección general y pública; vid. Albanese (2002).

99 Ya por tratarse sobre cuestiones específicamente referidas a ciertos colectivos, de manera que sus miembros se consideran como sujetos preferentes respecto a cómo determinar sus propias relaciones y conducta (desde hace tiempo la actividad deportiva, y más recientemente la autorregulación de internet); ya por referirse a materias muy técnicas (incluso tecnológicas), en las que expertos y técnicos se presentan como mejor llamados a decidir y regularlas (normas técnicas); ya por tratar sobre materias y actividades que actúan a nivel global, de manera que sus actores o protagonistas se presentan como sujetos privilegiados a fin de determinar su normación (comercio internacional); o ya, y como una de las respuestas (o reacciones) que se da a la globalización (si bien no es algo nuevo), a la vista de la proliferación de grupos y colectivos que tienden a actuar de manera para-pública en ámbitos en los que los poderes públicos no terminan de 
Ahora bien, y desde esta dimensión, previniendo del carácter más corporativo, que verdaderamente democrático y plural, de la subsidiariedad en no pocos de los casos ${ }^{100}$, lo cual ha de tenerse en mente a la hora de conjugar adecuadamente la subsidiariedad horizontal como criterio articulador de ordenamientos privados con otros públicos en los que se definen intereses más generales y desde criterios y procedimientos democrático-pluralistas ${ }^{101}$.

Con ello se advierte la tensión dialéctica que la subsidiariedad supone siempre en relación a los múltiples principios y fines (complementarios, pero también contradictorios) que terminan por converger alrededor suyo (como democracia, eficiencia normativa, despolitización, descentralización, "Estado minimalista", etc.), así como el resultado abierto y dinámico que conlleva, frente al más estático principio de competencia, pues la subsidiariedad permite cambios relacionales de acuerdo a transformaciones futuras, sin necesidad de modificar un título competencial; de la subsidiariedad a modo ascensor, se llega a hablar ${ }^{102}$.

Finalmente respecto a la subsidiariedad se ha de indicar también su engarce con ocasión de las relaciones entre los Derechos nacionales y el internacional en materia de derechos humanos, en tanto que la garantía internacional de éste se activa cuando los primeros se muestran incapaces de ofrecer oportuno reconocimiento y efectiva garantía de aquéllos; o en caso de incertidumbre, una vez superado el margen de apreciación que los tribunales internacionales reconocen a favor de los Estados y sus respectivos ordenamientos ${ }^{103}$.

Todavía en un campo próximo a la competencia (y al de jerarquía, también), el principio de prevalencia da lugar a que en caso de conflicto de normas que per-

intervenir adecuada y oportunamente (como es el caso de las O.N.G. y otros colectivos y grupos en relación a los servicios sociales, ante la incapacidad, en no pocos casos, de una adecuada y oportuna intervención de los poderes públicos), de manera que ellos se estiman, entonces, mejor capacitados para intervenir. En torno a la autorregulación, vid.: Esteve Pardo (2002); y Simonetti (2009).

100 Ridola (2001), pp. 221-226.

101 Específicamente para el ámbito de internet (por ejemplo), vid. MuÑoz MaCHADO (2000), pp. 55-61. De ahí, volvemos a entender, que se presuponga una mayor capacidad de los ordenamientos públicos para redefinir, en última instancia y unilateralmente, las relaciones entre estos ordenamientos y los privados en atención al paradigma de la promoción y la garantía de intereses generales y abstractos política y democráticamente establecidos.

102 Bin y Pitruzzella (2001), p. 96.

103 Por ejemplo, Bilancia (2006). Mas ello, sin perjuicio de la expresa institucionalización de la subsidiariedad en tal ámbito, como resulta en la disposición transitoria vigesimocuarta de la Constitución chilena respecto a la Corte Penal Internacional. 
tenecen a diversos ordenamientos jurídicos las normas de uno de ellos se apliquen siempre en detrimento de las del otro, las cuales resultan así sistemáticamente desplazadas mas sin verse afectadas en su validez ahora ${ }^{104}$; y de esta forma que la prevalencia se refiera al ámbito de actuación de los aplicadores del Derecho (en particular de los jueces) y con ocasión de la resolución de conflictos normativos interordinamentales, sin perjuicio de reconocer cierta proyección refleja e indirecta sobre los sujetos normativos en cuanto que sabedores de la eficacia de sus normas en relación a las de otro ordenamiento cuya relación viene determinada por tal prevalencia (de unas, u otras) ${ }^{105}$. En cuanto a en qué supuestos de relaciones entre ordenamientos jurídicos vienen actuando la prevalencia (y sin perjuicio de las modulaciones que al respecto cabe advertir, conforme a específicos desarrollos de la misma según supuestos), el conjunto es amplio, pues abarca: desde casos de subsunción y concurso de ordenamientos ante otro superior (y siempre que no intervenga el principio de competencia, pues entonces predomina éste, de forma que la prevalencia resulta desactivada, a salvo de su consideración como criterio meramente provisional), y del que resulta como manifestación específica la preemption norteamericana; a casos de integración ordinamental, como es la primacía del Derecho europeo frente al de los Estados miembros; y la prevalencia o primacía del Derecho internacional ${ }^{106}$.

Respecto a la prevalencia en los sistemas descentralizados territorialmente, ésta vendría de manera natural a proyectarse sobre ámbitos de competencias no exclusivas ${ }^{107}$, por cuanto que sólo en tal ámbito, como se ha indicado previamente, no actuaría el ya referido principio de competencia; sin embargo, el intenso desarrollo que del principio de competencia se ha apreciado en Derecho comparado (durante el S. XX), ha dado lugar a que la prevalencia se plantee como un criterio

$104 \mathrm{Al}$ no existir quebranto de normas sobre producción jurídica, como sí sucede con la competencia y la jerarquía. Cfr. Balaguer Callejón (1991a), pp. 156-158.

105 Vid. De La Quadra-Salcedo Janini (2009), en especial p. 221.

106 De especial interés sobre la relación entre competencia y prevalencia, conforme a su evolución histórica y desde el Derecho comparado, según que se trate de procesos de integración o de devolución (de manera que en los primeros tiende a actuar un concepto flexible de competencia y articulándose entonces las relaciones ordinamentales a través de la prevalencia, mientras que en los segundos se da un concepto ya estricto de competencia, y excluyéndose entonces la prevalencia), Biglino Campos (2007), en especial Capítulo IV.

107 Decimos de natural, pues cabe que constitucionalmente se establezcan otras respuestas como acontece en la actualidad en el caso alemán a la vista del artículo 84.1 de su Constitución, a favor de un criterio cronológico del Derecho federal sobre el de los Länders, que pasaría a quedar derogado. 
secundario, residual, ante aquél ${ }^{108}$, de forma que, según se viene indicando, la prevalencia cede finalmente ante la competencia ${ }^{109}$.

En esta última línea, la preemption, y como concreción de la prevalencia en sistemas compuestos (según lo visto más arriba, y en desarrollo antes del S. XX, cuando aún el principio de competencia no estaba normativamente implantado), encuentra principal manifestación en el artículo VI.2 de la Constitución de los Estados Unidos de Norteamérica, conforme al cual: tanto la Constitución federal, como las leyes federales de los Estados Unidos que se aprueben con arreglo a la misma, y los Tratados celebrados por éste, son Derecho supremo; además, vinculan a los jueces de los diferentes Estados, y no podrán resultar afectados por las Constituciones o las leyes de éstos. Así, y en principio, vendría a establecerse en el orden federal norteamericano una regla de resolución de conflictos en virtud de la cual los jueces, tanto federales como estatales, han de dar prevalencia al Derecho federal frente al estatal, de manera que el segundo resulta desplazado por el primero en su aplicación ${ }^{110}$. Sin embargo, al tiempo, la preemption presenta en su realización una mayor proyección (cuasi estructural, ahora), al permitir que la Federación vete, impida o bloquee el poder normativo de los Estados en materias que han sido efectivamente reguladas por ésta ${ }^{111}$. Y es que, a pesar de que a la postre podamos reconocer un marco competencial entre la Federación y los

108 Argullol I Murgadas y Velasco Rico (2011), pp. 39-40. Y así que, para el caso de España (por ejemplo), y ante la preponderancia alcanzada por la competencia, la prevalencia haya llegado a ser considerada por parte de la doctrina como innecesaria (TEJEDOR BIELSA (2000), pp. 45-105, y 203), sin perjuicio de lecturas de la misma más abiertas, en especial con ocasión de la legislación autonómica de desarrollo cuando ésta entra en conflicto con la legislación básica estatal posterior a aquélla, como así apuntara ToRnos MAS (1991). Con todo, se ha de advertir cómo tal lectura de ordinario tan estrecha sobre la prevalencia del Derecho estatal sobre el autonómico en el sistema español conecta, a su vez, con la rígida sujeción del juez español al imperio de la ley (artículo 117.1 Constitución Española), de manera que éste no puede por sí inaplicar ley alguna postconstitucional, debiendo siempre acudir a la cuestión de inconstitucionalidad (artículo 163 Constitución Española), y decantándose la cuestión finalmente desde el criterio de competencia, según Leguina Villa (1993); al respecto, particularmente interesante resulta la Sentencia del Tribunal Constitucional español 66/2011, de 16 de mayo, y su voto particular.

$109 \mathrm{Y}$ es que las competencias, a su vez (y por definición), vienen a ser (en principio) exclusivas, salvo que de manera excepcional quepa que sobre una misma materia dos o más sujetos puedan desarrollar unas mismas funciones o facultades; ARROYO GIL (2009). Con todo, cabe encontrar manifestaciones expresas de la prevalencia, como son los casos de Suiza, donde el Derecho federal prima, de modo genérico y abstracto, sobre el Derecho cantonal que le sea contrario (artículo 49.1 Constitución Suiza); o el de Australia, para supuestos en los que los Estados tienen competencia, y aun así la Federación interviene legítimamente (artículo 109 Constitución Federal).

110 Sobre la preemption en Estados Unidos, vid. TRIBE (2000), pp. 1172 y ss.

111 Desde esta perspectiva, vid. Velasco Caballero (2011). 
Estados parte de la misma, la potencialidad de ciertas competencias reconocidas a la Federación ante los Estados y sus potestades normativas (en especial, la cláusula de comercio, pero también más recientemente seguridad nacional y terrorismo) es lo que consiente a la primera oponerse a los segundos, a través de la preemption, una vez que ésta ha aprobado una norma con un determinado grado de extensión que entraría en un ámbito inicialmente accesible para los Estados ${ }^{112}$.

Con relación a la primacía, ahora, del Derecho de la Unión Europea respecto a los Derechos de los Estados miembros, destaca su consideración como elemento clave (cuasi constitucional) en la conformación jurídica del Derecho Europeo; y ello, sin que aún la primacía haya sido institucionalizada (positivizada) en los Tratados constitutivos ${ }^{113}$. En cuanto al alcance de la misma, se recuerda que la primacía supone, de primeras, el mero desplazamiento del Derecho nacional por el Derecho de la Unión con ocasión de su aplicación, sin suponer que tal contradicción conlleve juicio de validez, en principio, para el Derecho nacional, siempre y cuando, claro está, el propio Derecho de la Unión sea conforme al marco competencial anteriormente referido ${ }^{114}$. Pero entonces, ¿cómo es posible que se active la primacía del Derecho europeo, en tanto que modalidad de la más genérica prevalencia, bajo condición de validez del propio Derecho europeo conforme al marco competencial del mismo, cuando ello, por sí, activaría el propio principio de competencia? La razón vendría, conforme se ha señalado antes, en cómo, al día de hoy, la adecuación del Derecho europeo a dicho marco competencial no conlleva de manera directa un juicio de validez del Derecho nacional (más allá,

112 Por tanto, y sin perjuicio de los efectos de bloqueo político-normativo que la preemption presenta en los Estados Unidos, ésta continúa articulándose en el seno de un marco competencial si bien no exclusivo para la Federación. De lo contrario, ya no se hablaría de preemption, sino de competencias exclusivas; cfr. Rosen (2008).

113 Al margen del malogrado intento en 2004 del Tratado por el que se establece una Constitución para Europa (artículo I-6). Decía así el artículo I-6: "La Constitución y el Derecho adoptado por las instituciones de la Unión en el ejercicio de las competencias que se le atribuyen a ésta primarán sobre el Derecho de los Estados miembros". No obstante, la preliminar contundencia de este precepto resultaba ya rebajada a la vista de la Declaración relativa al artículo I-6 aneja al Acta final de la Conferencia intergubernamental y Acta final, en virtud de la cual, ahora: "La Conferencia hace constar que el artículo I-6 refleja la jurisprudencia existente del Tribunal de Justicia de las Comunidades Europeas y del Tribunal de Primera Instancia”. Con todo, sobre las posibilidades constitucionales que abría el artículo I-6, SÁNCHEZ BARRILAO (2004b), pp. 138-144.

114 Ahora, Declaración 18 relativa a la primacía, aneja al acta final de la Conferencia Intergubernamental que ha adoptado el Tratado de Lisboa y Dictamen del Servicio Jurídico del Consejo sobre la primacía, de 22 de junio de 2007; también, vid. artículo 5.1 del Tratado de la Unión Europea. Con todo, parecería haberse rebajado el alcance de la primacía, ante la anteriormente recogida en el Tratado constitucional, pues ahora se guarda silencio en relación al principio de competencia; cfr. ROdRíguEZ-IzQUiERDo SERRANO (2011), pp. 103-105. 
eso sí, de la cuestión prejudicial y la exigencia de responsabilidad estatal a manos del Tribunal de Justicia), siendo por tanto que la primacía siga actuando en un plano de aplicabilidad, que no de validez, de normas (europeas y estatales) en confrontación ${ }^{115}$; además se ha de advertir cómo el Tribunal de Justicia no ha venido precisamente a potenciar la dependencia de la primacía del Derecho europeo respecto al marco competencial de la Unión, como demuestra la escasísima e irregular jurisprudencia relativa a ello ${ }^{116}$. Otra cosa es, obviamente, que el principio de primacía se encuentre expresamente constitucionalizado a nivel estatal, como sucede en el caso irlandés (artículo 29.4 de la Constitución irlandesa), de manera que quepa entonces potenciar la primacía del Derecho europeo como parámetro de enjuiciamiento constitucional estatal ante el Derecho interno; como en su caso sería llegar a contar con una auténtica Constitución europea, por cuanto que, entonces sí, cabría conectar competencia con supremacía, y dando lugar, por tanto, a una primacía como mero instrumento provisional ante un auténtico juicio de validez sobre dicha confrontación normativa ${ }^{117}$.

115 Sobre esto último, en tal sentido, TrSTEnjaK (2013), p. 72. Cuestión específica es cómo el silencio normativo por la Unión Europea en un ámbito competencial de la misma no sea entendido como laguna digna de ser resuelta, sino como supuesto de desregulación, de manera que tal silencio normativo (que no político y jurídico) desregulatorio, que pueda ser defendido por la Unión ante los Estados a fin de evitar que éstos normen el supuesto de hecho desregularizado; ello, entonces, entronca con la referida preemption, según AZPITARTE SÁNCHez (2004), p. 87.

116 Lo ha puesto de manifiesto Rodríguez-Izquierdo SERrano (2011), pp. 175 y ss. Y es que el Tribunal de Justicia, no se olvide, se resiste a perder su genuina condición de garante del Derecho de la Unión (en especial su carácter autónomo y su efectividad ante los Derechos estatales) frente a las referidas concepciones pluralistas del Derecho europeo (ya referidas), como en relación a una consideración más constitucionalista del mismo apegada ahora a la garantía de los derechos de las personas, tal como señala AzPiTARTE SÁNCHEz (2013).

117 Por otra parte se ha de advertir la propuesta, por tiempo, de una acepción maximalista de la primacía del Derecho europeo a la vista: de un lado, de ciertos intentos por parte del Tribunal de Justicia de conferir mayores consecuencias en relación al Derecho interno, como por ejemplo en el sentido de impedir la formación válida de nuevos actos legislativos nacionales en la medida en que sean incompatibles con las normas comunitarias (nuevamente, Sentencia Simmenthal II); de otro, de la posición del Tribunal de Justicia como garante del cumplimiento por los Estados de sus obligaciones con la Unión, a la par que de la aplicación uniforme del Derecho europeo; y por último, de la proposición incondicionada de extensión automática de tal primacía a cualquier manifestación normativa estatal por los jueces nacionales. Por todos, en este sentido, RUIZ-Jarabo Y Colomer (1993). Sin embargo tal proyección de la primacía del Derecho de la Unión Europea respecto a los Derechos nacionales en abstracto, incluyendo los propios Derechos constitucionales nacionales (en especial, Sentencia del Tribunal de Justicia de 17 de diciembre de 1970, Internationale Handelsgesellschaft), se ha visto condicionada ante la progresiva posición adoptada por algunos Tribunales Constitucionales en favor de la garantía de un núcleo duro de sus respectivas Constituciones ante el Derecho europeo (al tiempo, los llamados "contralímites"), llegando a su ulterior institucionalización; y así, dando lugar, finalmente, a que la primacía del Derecho europeo resulte hoy sometida a cierta relativización desde el pluralismo jurídico 
Y respecto al Derecho internacional, por último, ciertamente la articulación del Derecho internacional con relación a los Derechos internos según el carácter dual o monista de la concepción que sobre la misma predomine en un sistema concreto, y al hilo de ello la específica previsión que constitucionalmente se defina sobre tales relaciones, marca, casi caso a caso, cómo efectivamente se plantea tal relación ${ }^{118}$. Con todo, cabe advertir cómo el Derecho internacional (en particular, en su dimensión más convencional) se presenta genéricamente de aplicación prevalente o con primacía ante el Derecho interno infraconstitucional, viniéndolo a desplazar únicamente; otra cosa es, con todo, que en algunos ordenamientos constitucionales se prevea la entrada del Derecho internacional en un nivel cuasiconstitucional, de manera que, sin quedar la Constitución subordinada a éste, sí que un quebranto del Derecho infraconstitucional nacional al internacional pueda ser entendido como un quebranto a su vez a la misma Constitución ${ }^{119}$.

E igualmente habría que decir respecto al Derecho internacional y el Derecho de la Unión Europea, en tanto que ésta ostenta personalidad jurídica (artículo 47 del Tratado de la Unión Europea) y puede celebrar tratados internacionales con otros Estados e instituciones internacionales (artículos 37 del Tratado de la Unión Europea, y 3.1 y 209.2, y Título V, del Tratado de Funcionamiento de la Unión Europea), de modo que tales tratados gozan de prevalencia, ahora, a nivel interno de la Unión Europea y de su Derecho'120; y a la par, que la articulación de dichos tratados internacionales respecto a los Estados miembros de la Unión se guíe, precisamente, mediante la primacía europea en cuanto que aquéllos son considerados, a la postre, como Derecho europeo derivado ${ }^{121}$.

que supone los Derechos constitucionales de los Estados miembros (HuBER (2013), pp. 89-91), por cuanto que aquél deriva limitado por éstos no sólo formalmente (principio de competencia), sino sustantivamente (identidades constitucionales de los Estados miembros); otra cosa es que esta última limitación resulte ahora expresada desde el mismo Derecho europeo (otra vez, artículo 4.2 del Tratado de la Unión Europea), de forma que el propio Tribunal de Justicia, paradójicamente, sea competente para definir la extensión de tal limitación, sin perjuicio, eso sí, de poder entrar en diálogo/confrontación con los Tribunales constitucionales nacionales afectados en su caso, según nos advierte VeCCHIO (2012b).

118 Vid. Peters (2009).

119 Este sería el caso de Alemania, artículo 25 de la Constitución; Hillgruber (2004), en especial p. 123.

120 Sentencia del Tribunal de Justicia Comisión v. Alemania, de 10 de septiembre de 1996.

121 Esto, así, plantea problemas para el Derecho de la Unión Europea y la función de garantía que al respecto del mismo desarrolla el Tribunal de Justicia ante tales tratados, como se puso de manifiesto con ocasión del Dictamen 1/09, del propio Tribunal, de 8 de marzo de 2011 (sobre compatibilidad de un proyecto de acuerdo por el que se crea un sistema unificado de resolución de litigios sobre patentes), y más recientemente a la hora de la vigente negociación de la adhesión por la Unión Europea del Convenio Europeo de Derechos 
Otra cosa es, por último (pero en estrecha relación a lo anterior), que los Estados miembros de la Unión Europea puedan a su vez articular mediante instrumentos internacionales actuaciones paralelas a la Unión Europea y a su ordenamiento (y al margen, incluso, de la cooperación reforzada -artículo 20 del Tratado de la Unión Europea-), como por ejemplo acontece con el muy polémico Tratado Constitutivo del Mecanismo Europeo de Estabilidad (MEDE), de 2 de febrero de $2012^{122}$.

\section{RELACIONES HORIZONTALES Y DERECHO COMPARADO}

Ya por último, en cuanto a supuestos en los que sin título expreso (y sin conllevar situaciones de dependencia o limitación ordinamental) generan, no obstante y de manera efectiva, puestas en contacto entre ordenamientos jurídicos, la instrumentación del Derecho comparado como criterio interpretativo del Derecho por los aplicadores jurídicos ${ }^{123}$, y en especial por los jueces (de manera que la interpretación del Derecho se expande a otros ordenamientos), pone finalmente en relación (a veces de manera bastante intensa) a distintos ordenamientos jurídicos, abriéndose unos a otros a modo de diálogo horizontal ${ }^{124}$; y ello, de forma particular, en el contexto de la globalización, en el que los aplicadores del Derecho acuden en la interpretación de normas jurídicas propias (e incluso en la búsqueda de la norma aplicable al caso) a normas de otros ordenamientos jurídicos

Humanos (conforme al artículos 6.2 del Tratado de la Unión Europea, y 218.6.a.ii y 8 del Tratado de Funcionamiento de la Unión Europea). Tal adhesión sí que supondrá una articulación más intensa entre el Derecho de la Unión, el Convenio Europeo y los Derechos nacionales (asunto Akerberg Fransson, en Sentencia del Tribunal de Justicia de la Unión Europea de 26 de febrero de 2013), además de proveerse, entonces, de consecuencias jurídicas (responsabilidad) para la Unión en caso de quebranto de aquél.

122 Y según lo admitido por el propio Tribunal de Justicia de la Unión Europea en el asunto Pringle (Sentencia de 27 de noviembre de 2012). Al respecto, vid.: Martín Y Pérez De Nanclares (2012); Van Malleghem (2013).

123 Sobre la comparación jurídica como "quinto" método de interpretación (y como comparación cultural, incluso), vid., por todos, HäBERLE (2001), pp. 162-165.

124 Importante es remarcar dicha consideración horizontal frente a supuestos en los que los tribunales propios de un ordenamiento sí están jurídicamente sujetos a otro, como acontece en España, por ejemplo, a la vista del artículo 10.2 de la Constitución española en relación a la interpretación de los derechos fundamentales (según se ha comentado). Así, respecto a una clara distinción entre comunicación transjudicial horizontal y vertical, vid. Nogueira Alcalá (2011); y acerca del artículo 10.2 CE, y de la relación entre los tribunales españoles y el Tribunal Europeo de Derechos Humanos, entre otros, Guillén López (2011). 
(aun por distintos motivos) ${ }^{125}$ con los que, en principio, vendrían a mantener una comunicación cultural común de valores ${ }^{126}$.

Así que la comparación pueda presentarse, precisamente, no sólo como manifestación de una identidad ordinamental que depende cada vez más de su alteridad con otros en relación a valores compartidos ${ }^{127}$, sino como instrumento o vía de articulación de una auténtica cooperación, relación, ordinamental: de manifestación del "stato costituzionale cooperativo" ${ }^{128 .}$. Es a la vista de ello que se pueda hablar, entonces, de una verdadera globalización del Derecho en ciernes con relación a concretos y particulares sectores materiales en los que existe, o va generándose, una conciencia común de valores globalmente compartidos (en especial, en materia de derechos humanos o en medio ambiente, y en determinadas parcelas), que vendría luego a desplegarse e interactuar en el seno de los diversos ordenamientos jurídicos ${ }^{129}$; e incluso que, desde tal perspectiva y a su vez, cabe advertirse un título jurídico, aunque difuso, en la instrumentación de relaciones entre ordenamientos con ocasión del Derecho comparado respecto a sectores en los que cabe apreciar dicha concepción común y compartida, y al hilo de la cada

125 Ya, para integrar lagunas, solventar dificultosas interpretaciones, resolver casos nuevos, fundamentar cambios de anteriores pareceres, legitimar las propias decisiones al amparo de la autoridad del referente comparado, promocionar el propio rol ante la comunidad internacional o meramente, e incluso, dar mayor ornamentación a la argumentación jurídica; cfr. PinTO BASTOS Junior (2007), p. 252.

$126 \mathrm{Al}$ respecto de la actuación judicial y del Derecho comparado en tal sentido, vid. Pizzorusso (2005), pp. 30-33; y Pérez Luño (2011), pp. 86 y ss. De este modo, por ejemplo, cabe señalar la Sentencia del Tribunal Constitucional español 198/2012, de 6 de noviembre de 2012, relativa a la constitucionalidad del matrimonio entre personas del mismo sexo en España, y en la que se cita expresamente la Sentencia de 9 de diciembre de 2004 del Tribunal Supremo canadiense (asimismo, sobre el matrimonio entre personas del mismo sexo); o la Sentencia del Tribunal Supremo Federal norteamericano de 26 de junio de 2003, en el caso Lawrence vs. Texas, sobre la inconstitucionalidad de la punición de relaciones sexuales consentidas entre personas del mismo sexo, y en la que aquél acudía ahora al parecer del Tribunal Europeo de Derechos Humanos (Sentencia de 23 de septiembre de 1981, en el caso Dudgeon vs. United Kingdom); o, por último, la Sentencia de la Corte Interamericana de Derecho Humanos de 24 de febrero de 2012, en el caso Atala Riffo y niñas vs. Chile, en la que, al respecto de una discriminación por motivos de orientación sexual, se invoca también diversas Sentencias del Tribunal Europeo de Derechos Humanos (en particular, la del caso Salgueiro da Silva Mouta vs. Portugal, de 21 de diciembre de 1999).

127 SChillaci (2012a), pp. 24-34.

128 Siguiendo a HäBERLE, nos habla Ridola (2010) respecto al uso del método interpretativo comparado por los propios Tribunales constitucionales (p. 293); incluso, como una "forma suave" de la internacionalización del orden constitucional, Herdegen (2010) presenta la comparación (pp. 79-80), en tanto que vehículo de conformación de un Derecho común a nivel regional y/o internacional. En este último sentido, ya, HÄBERLE (2000a), pp. 289-290.

129 En esta perspectiva, de interés, Del Toro Huerta (2005). 
vez mayor apertura, comunicación y cooperación entre Estados (y ordenamientos) en ciertas y concretas materias ${ }^{130}$.

Cierto, con todo, que tal tipo de relación no supone, en principio, vinculación jurídica efectiva entre ordenamientos y jurisdicciones ${ }^{131}$. Mas ello, salvo que tal invocación autónoma se haga en términos auto-vinculantes y pro futuro, o finalmente, insistimos, quepa deducirse un marco constitucional común efectivamente compartido, abierto y hetero-referencial del propio ordenamiento jurídico particular; un hito al respecto, entendemos, fue precisamente la ya citada consideración por el mismo Tribunal de Justicia en relación al Convenio Europeo de Derechos Humanos (y con esto, la jurisprudencia del Tribunal Europeo de Derechos Humanos), junto a las tradiciones constitucionales de los Estados miembros, como expresión de un acervo o patrimonio constitucional común a nivel europeo ${ }^{132}$, y en tanto que principios generales del Derecho comunitario y parte del Derecho originario comunitario ${ }^{133}$, y así como criterio de validez del propio Derecho comunitario derivado ${ }^{134}$. Y ello, ante la dificultad jurídica y política de hacer valer la más que limitada legitimación democrática de unas originarias Comunidades Económicas Europas y de su Derecho derivado (ensimismado en una percepción esencialmente funcional del Derecho comunitario) frente a los ordenamientos constitucionales de sus Estados miembros, y la incidencia en los mismos del reconocimiento y garantía de derechos fundamentales de la persona ${ }^{135}$.

130 Y al amparo de ello, un renovado ius communicationis, según Pérez Luño (2011), pp. 86-88.

131 Como señala Nogueira Alcalá (2013b), pp. 223-227. De ausencia de diálogo, incluso, nos habla DE VergotTini (2010).

132 HäBerLe (1993), en especial pp. 18-20.

133 Entre otras, las citadas Sentencias del Tribunal de Justicia Nold y Hauer.

134 Sobre la consideración normativa del Derecho constitucional común europeo relativo a los derechos fundamentales, cfr. Azpitarte SÁnchez (2005), pp. 352-356; e incluso, sobre el reforzamiento mismo del Convenio Europeo de Derechos Humanos al ser asumido por el Tribunal de Justicia como Derecho originario, y por tanto proyectarse ahora sobre los Derechos nacionales al amparo del principio de primacía, vid. Huber (2013), p. 135.

135 Vid., entre otros, Gambino (2009), pp. 39-49 y 54-57. Otra cosa es (y según se ha visto), al hilo del Tratado de Maastricht (y el de Ámsterdam), la expresa positivización, ya referida, de tal patrimonio constitucional común en derechos fundamentales en el Tratado de la Unión Europea (nuevamente, y respectivamente, artículos F.2 y 6.2); al respecto, Pizzorusso (2002), pp. 19-23. Y al tiempo, con el Tratado de Lisboa, la entrada en vigor de la Carta de los Derechos Fundamentales de la Unión Europea, además de, finalmente, la comentada garantía y previsión de la ratificación por la Unión del Convenio Europeo (artículos $6^{\circ}$ del Tratado de la Unión Europea y 218.6.a.ii y $8^{\circ}$ del Tratado de Funcionamiento de la Unión Europea, junto con la propia Carta). 


\section{Consideraciones FinAles}

A la vista de lo anterior (de cómo se desarrollan las relaciones entre los distintos ordenamientos jurídicos), se puede presentar diversos modelos desde los que, si no explicar y ordenar, sí al menos describir la enmarañada madeja de relaciones ordinamentales que hoy se advierte en el vigente y complejo contexto de la globalización. En tal sentido, precisamente, y desde las tesis de Pernice en torno a la integración europea ${ }^{136}$, es posible plantear, a nuestro entender, un primer modelo de multilevel ordinamental global, en virtud del cual los diversos ordenamientos jurídicos y sus relaciones se proyectarían parcial y verticalmente desde el plano local, a los más amplios estatal, regional e internacional, si bien en un marco dinámico y dialéctico de recíprocas influencias e intercomunicación ${ }^{137}$; y ello, además, en atención a los distintos sectores materiales en los que unos y otros mejor y más eficientemente pueden desarrollar su ordenación, en clara correspondencia a un planteamiento de subsidiariedad vertical ${ }^{138}$.

No obstante, el anterior modelo presenta, a nuestro entender, varios problemas. El primero entronca con la referencia a como, en el contexto jurídico global en el que se enmarca este trabajo, determinados ordenamientos estatales hoy pujantes (emergentes), pero deficitarios constitucional y democráticamente (a nivel comparado), difícilmente encajarían en dicho esquema multinivel al partir (fundamentarse) dicha propuesta de esquema de un estadio constitucional culturalmente compartido ${ }^{139}$. Y en cuanto a la segunda objeción que apreciamos en relación al modelo multinivel, ésta giraría ahora sobre su evidente dimensión vertical, pues: de un lado, tal articulación superpuesta de los ordenamientos jurídicos denota finalmente cierta preeminencia de unos ordenamientos respecto a otros (aun sin entrar en una dinámica jerárquica) ${ }^{140}$, lo cual, y más allá del ámbito

\footnotetext{
136 Pernice (1999) y (2012).

137 Para una propuesta de constitucionalismo multinivel a nivel global, desde el modelo europeo, vid. Petersmann (2006).

138 Por ejemplo, y en relación al cambio climático, vid. SсOTт (2011).

139 Sobre tal estadio vid. HäBERLE (2000b), pp. 33-38. Estadio, a su vez, reforzado por la confluencia de los rasgos básicos de los diversos Derechos constitucionales nacionales al amparo, precisamente, de la integración europea, según CruZ Villalón (2013), a la vez que ésta es hoy parte de las respectivas identidades de aquéllos (PAulus (2013), p. 64). Mas todo ello, sin perjuicio de reconocer la progresiva apertura de tales ordenamientos emergentes (los constitucionalmente deficitarios, claro está) a otros como consecuencia precisamente de su necesaria relación con ellos al amparo de la globalización económica y su efectiva preponderancia en el mercado mundial.
}

140 Como señala NúÑ́z Poblete (2004), pp. 126-130. 
infraestatal, no termina de darse en razón al aún preponderante papel y al carácter independiente (aunque limitado) de los ordenamientos estatales (en particular, con ocasión de los referidos ordenamientos emergentes); y de otro, que olvida ahora las relaciones horizontales entre ordenamientos jurídicos, y singularmente cuando de ordenamientos no públicos se trata ${ }^{141}$.

Es en atención a esta última objeción, así como al preponderante papel que los operadores jurídicos (en especial los jueces) desarrollan en la efectiva articulación de las relaciones entre ordenamientos jurídicos en el vigente contexto global ${ }^{142}$, que quepa hoy expresar las relaciones ordinamentales a modo de red ${ }^{143}$ : las normas jurídicas que se integran en un concreto ordenamiento entran en su realización práctica, como Derecho vivo, en múltiple contacto con otras de otros ordenamientos tanto públicos, como no públicos, y según los principios e instrumentos anteriormente indicados; y por tanto, desde un plano tridimensional de nodos ordinamentales. Y es que las normas jurídicas en su realización, además de interactuar con las normas de su propio ordenamiento, conectan en mayor o menor grado con otras múltiples pertenecientes a diversos ordenamientos que, en razón a la materia, resultan finalmente de aplicación e interacción según los jueces ${ }^{144}$. Y de esta manera cómo el parámetro de resolución jurídica de un caso en cuestión termina por definirse a la luz de la interacción de diversas normas pertenecientes a distintos ordenamientos ${ }^{145}$; e incluso, que desde parámetros propios de un ordenamiento jurídico, los jueces juzguen y resuelvan sobre aspectos o ámbitos de otros (sobre los que, en principio, no existe conexión jurídica y/o jurisdicción directa) ${ }^{146}$. Se viene así a definir autén-

141 WaLKer (2009), en especial pp. 20-23.

142 CASSESE (2010).

143 Ost y Van De Kerchove (2000).

144 No se olvide que, y sólo en relación al proceso de integración europea, la primacía del Derecho de la Unión ante el estatal, en cuanto que principio protagonista de las relaciones del Derecho europeo y de los Estados miembros, es aún de conformación jurisdiccional. O cómo los jueces, a la hora de buscar la interpretación más adecuada de una norma jurídica en su realización y aplicación, acuden hoy a un Derecho que está en hipertexto, y que permite una rápida confrontación de respuestas jurídicas comparadas al caso según el sistema jurídico de referencia. O cómo los sujetos y operadores del tráfico económico optan, cada vez más, por sistemas jurídicos y jurisdiccionales de referencia proclives a sus respectivos intereses, a modo de auténtico turismo y/o mercadeo jurídico en la aldea global. O cómo los propios poderes públicos optan, también cada vez más, por regulaciones abiertas a otros sistemas jurídicos, tanto públicos como no públicos, que los jueces finalmente implementan a nivel interno.

145 De "legalidad porosa” en relación a “un ordenamiento jurídico difuso", PérEz LuÑo (2011), pp. 92-93.

146 Como ha acontecido en los asuntos Kadi, con el Tribunal de Justicia de la Unión Europea (Sentencia de 3 de septiembre de 2008) en relación a Naciones Unidas (relativa a la validez de actos comunitarios que 
ticas "líneas rojas" entre ordenamientos y jurisdicciones ${ }^{147}$, y con ello, a esbozarse controles y límites horizontales del poder y del Derecho, a modo de renovado y globalizado principio de división de poderes en garantía de los derechos.

Con todo, el anterior modelo sobre las relaciones ordinamentales en el contexto global si bien permite una descripción bastante aproximada a la realidad jurídica, evidencia la pérdida del peso del elemento político-normativo ante el más preponderante jurisdiccional en la articulación y estructuración de dichas relaciones. Ciertamente una praxis judicial continuada al respecto de una concreta relación internormativa e interordinamental vendrá al tiempo a concretar el sentido u orientación de la relación, lo que otorga cierta seguridad jurídica (en tanto que previsibilidad) a la postre en la referida relación; pero también es cierto que se corre el riesgo de que tal sentido u orientación pierda sustrato democrático-político, al quedar finalmente en manos de los jueces ${ }^{148}$. No en vano, tal concreción judicial de las relaciones ordinamentales parte de casos concretos, lo que, más allá de su importancia como método para la decantación de nuevos principios sustantivos, como relacionales (o nuevas proyecciones o modulaciones de los existentes), carece de la racionalidad abstracta que aún se presupone a la potestad normativa con carácter general. No es que los jueces no deban ejercer un rol primordial en la articulación de las relaciones entre ordenamientos, pues su actuación resulta esencial para su efectiva interrelación sistémica, a la par que los jueces son aplicadores cualificados del Derecho mediante la realización concreta de la norma jurídica a fin de garantizar los derechos de las personas; ni que los jueces, incluso, no gocen de legitimidad. Es sólo que no debemos resignarnos a perder la orientación política, la legitimación democrática y la racionalidad de cómo queramos que se estructuren las relaciones de las normas que integran nuestros respectivos ordenamientos con otros, pues, en última instancia, lo contrario acabará teniendo repercusión en la conformación misma e interna de nuestros Derechos u ordenamientos jurídicos (según se ha mostrado) ${ }^{149}$.

implementan resoluciones del Consejo de Seguridad, y al amparo de ello, sobre las propias resoluciones), y M.S.S. c. Bélgica y Grecia, con el Tribunal Europeo de Derechos Humanos ahora (Sentencia de 21 de enero de 2011), respecto a la Unión Europea [en la que se condena a Bélgica por dos violaciones del derecho a no ser sometido a tratos inhumanos o degradantes (artículo $3^{\circ}$ del CEDH) por las consecuencias del traslado efectivo de un demandante de asilo a Grecia en aplicación del sistema de Dublín (Reglamento (CE) 343/2003, de 18 de febrero de 2003, de determinación del Estado responsable del examen de una solicitud de asilo (Dublín II)].

147 Gordillo Pérez (2012a), pp. 499-501.

148 JACQUÉ (2007), pp. 35-37.

149 No en vano la actuación judicial en el contexto globalizado, según se ha apuntado más arriba, viene a potenciar la jurisprudencia como fuente del Derecho; Xiol Ríos (2009), pp. 123-131). Ello obviamente 
De esta forma, ya que los Derechos u ordenamientos más esenciales siguen siendo los estatales (a pesar de su crisis), tanto en su dimensión total como compuesta (es decir, integrando los ordenamientos que a su vez formen parte de él), y éstos en buena medida vienen determinados por Constituciones democráticonormativas, parecería adecuado profundizar en las mismas a fin de que éstas, mediante oportunas reformas, mantengan un efectivo y equilibrado control de su apertura a otros ordenamientos ${ }^{150}$. Y tampoco debería obviarse la posibilidad de profundizar constitucionalmente en el marco internacional, pues, sin llegar a instar un auténtico proceso de constitucionalización del Derecho internacional (lo cual queda hoy bastante lejos...), lo que sí cabe es articular más instrumentos e institutos constitucionales desde este ámbito ${ }^{151}$.

\section{BiBLIOGRAFÍA CITADA}

Aláez Corral, Benito (2012): "Soberanía estatal, supremacía constitucional e integración europea a la luz de la jurisprudencia del Tribunal Constitucional Federal Alemán”, en TRC (No 30), pp. 359-385.

Albanese, Alessandra (2002): "Il principio di sussidiarietà orizzontale: autonomia sociale e compiti pubblici”, en Diritto pubblico (No 1), pp. 51-84.

AlmeIDA, Wojcikiewicz (2009): "A execução do Direito da integração do MERCOSUL: uma limitação da autonomia dos Estados partes”, en Novos Estudos Jurídicos (Vol. XIV, No 1), pp. 155-167.

Alonso García, Ricardo (1994): Derecho comunitario. Sistema constitucional y administrativo de la Comunidad Europea (Madrid, CEURA), p. 673.

cataliza, a su vez, transformaciones de los ordenamientos públicos de tradición civil law en relación a los de common law; Pizzorusso (2009), especialmente pp. 246-247 y 314.

150 Respecto al proceso de integración europea (y en tanto que patrón de proceso de integración regional en Derecho comparado), debería asimismo profundizarse en su conformación constitucional por cuanto que, al margen de que la supervivencia misma de la Unión Europea en el actual contexto de globalización y crisis dependa de su mayor integración (lo que obviamente exige de una mayor profundización constitucional sustantiva, como formal), el actual estadio de relaciones de su ordenamiento con los de los Estados miembros así lo requiere dado que aún la primacía del primero con los segundos ni siquiera está positivizada, institucionalizada (según lo comentado), dejando un amplio margen al diálogo (y al conflicto) entre el Tribunal de Justicia y los Tribunales constitucionales de los Estados.

151 Ello muy posiblemente vendría no sólo a garantizar una mejor interrelación del propio Derecho internacional con el resto de los ordenamientos jurídicos vigentes (en particular con los estatales y con los derivados de procesos de integración, más también con aquéllos no públicos pero de proyección internacional), sino a la mera (nada más, y nada menos) estabilización de dichas relaciones; GordiLlo Pérez (2012b). 
(2001): "El soft law comunitario", en RAP (No 154), pp. 63-94. (2006): "Los Tribunales Constitucionales ante el Derecho comunitario", en AA.VV. La articulación entre el Derecho comunitario y los Derechos nacionales: algunas zonas de fricción (Madrid, CGPJ), pp. 203-235.

ANDALUZ, Horacio (2010): "La estructura del sistema jurídico: Las relaciones entre las fuentes del Derecho en la Constitución vigente", en Anuario de Derecho Constitucional Latinoamericano (Vol. XVI), pp. 13-46.

Argullol I. Murgadas, Enric y Velasco Rico, Clara I. (2011): "Introducción", en AA.VV. Instituciones y competencias en los Estados descentralizados (Barcelona, IEA), pp. 17-80.

Arroyo Gil, Antonio (2009): "Competencia versus prevalencia en los Estados territorialmente descentralizados, con especial referencia al Estado autonómico español", en Revista Jurídica Universidad Autónoma de Madrid (No 20), pp. $195-217$.

Azpitarte SÁnchez, Miguel (2004): "Las relaciones entre el Derecho de la Unión y el Derecho del Estado a la luz de la Constitución europea", en ReDCE (No 1), pp. 75-95.

(2005): "Del Derecho constitucional común europeo a la Constitución europea. ¿Cambio de paradigma en la legitimidad de la Unión?”, en TRC (No 16), pp. 343-373.

(2013): "La autonomía del ordenamiento de la Unión y las 'funciones esenciales' de su sistema jurisdiccional”, en TRC (32), pp. 225-257.

Balaguer Callejón, Francisco (1991a): Fuentes del Derecho (Vol. I), (Madrid, Tecnos), 183 pp.

(1991b): "La integración del Derecho autonómico y la aplicación supletoria del Derecho estatal”, en RAP (No 124), pp. 95-147.

(1992): Fuentes del Derecho (Vol. II), (Madrid, Tecnos), p. 259.

(2003): "Las competencias de la Unión Europea y los principios de subsidiariedad y proporcionalidad", en REA (No 4), pp. 9-30.

(2008a): "La reforma constitucional en el contexto de la pluralidad de espacios constitucionales de dimensión europea”, en Boletín Mexicano de Derecho Comparado, pp. 29-61.

(2008b): "Subsidiariedad horizontal y vertical”, en AA.VV. Reformas estatutarias y declaraciones de derechos (Sevilla, IAAP), pp. 147-169. (2012a): La proiezione della Costituzione sull'ordinamento giuridico (Trad. Anna Maria Nico, Bari, Cacucci Editore), p. 109. 
(2012b): "Derecho constitucional e integración supranacional en el contexto de la globalización", en AA.VV. Constitución y democracia. Libro Homenaje a Antonio Torres del Moral. III (Madrid, Editorial UniversitariasCEPC-UNED), pp. 3039-3049.

BЕСК, Ulrich (1998): ¿Qué es la globalización? Falacias del globalismo, respuestas a la globalización, (Trad. María Rosa Borrás y Bernardo Moreno, Barcelona, Paidós), p. 299.

Biglino Campos, Paloma (2007): Federalismo de integración y de devolución: el debate sobre la competencia (Madrid, CEPC), p. 221.

Bilancia, Paola (2006): "Las nuevas fronteras de la protección multinivel de los derechos", en ReDCE (No 6), pp. 255-277.

Bin, Roberto (2002): Capire la Costituzione (Roma-Bari, Laterza), 199 pp.

Bin, Roberto y Pitruzzella, Giovanni (2001): Diritto costituzionale (segunda edición, Torino, G. Giappichelli Editore), p. 543.

BobBIo, Norberto (1991), Teoría general del Derecho (Trad. Eduardo Rozo Acuña, Madrid, Debate), p. 278.

CÁmara Villar, Gregorio (2005): "Los derechos fundamentales en el proceso histórico de construcción de la Unión Europea y su valor en el Tratado Constitucional", en ReDCE (No 4), pp. 9-42.

Cassese, Sabino (2002): La crisi dello Stato (Roma-Bari, Laterza), p. 144. (2009): Il diritto globale. Giustizia e democracia oltre lo stato (Torino, Einaudi), p. 244.

(2010): Los tribunales ante la construcción de un sistema jurídico global (Trad. Salvador Rodríguez Artacho y María Dolores Utrilla FernándezBermejo, Sevilla, Global Law Press), p. 278.

Chiti, Mario P. (2010): “¿Existe un Derecho público europeo? Una pregunta retórica”, en $R C D P$ (No 41), p. 15. Fecha de consulta: 17 de mayo de 2013. Disponible en http://www10.gencat.net/eapc_revistadret/revistes/Evolucio_i_ perspectives_del_dret_public._Especial_25e_aniversari_de_la_Revista_catalana_de_dret_public.

Clavero, Bartolomé (2013): "Constitucionalización mexicana de los derechos humanos, inclusive los derechos de los pueblos indígenas", en REDC (№ 97), pp. 181-199.

CRISAFUlli, Vezio (1970): Lezioni di diritto costituzionale (Vol. I), (segunda edición, Padova, CEDAM), 141 pp.

Cruz Villalón, Pedro (2004): La Constitución inédita: estudios ante la constitucionalización de Europa (Madrid, Trotta), p. 157. 
(2006): "La cláusula general europea”, en AA.VV. Hacia la europeización de la Constitución española: la adaptación de la Constitución española al marco constitucional de la Unión Europea (Bilbao, Fundación BBVA), pp. 51-74.

(2013): "Rasgos básicos del Derecho Constitucional de los Estados en perspectiva comparada", en AA.VV. El Derecho Constitucional en el espacio jurídico europeo (Valencia, Editorial Tirant lo Blanch), pp. 15-68.

D’Atena, Antonio (2010): "Las declinaciones de la subsidiariedad en el Derecho Constitucional italiano" (Trad. Martín Loo GutiérRez), en RDP (No 79), pp. 255-284.

De Julios-Campuzano, Alfonso (2009): La transición paradigmática de la teoría jurídica. El Derecho ante la globalización (Madrid, Dykinson), p. 250.

De La Quadra-Salcedo Janini, Tomás (2009): "Los principios de competencia y prevalencia como reglas de resolución de conflictos en el Estado Autonómico", en Revista Jurídica Universidad Autónoma de Madrid (No 20), pp. 219-238.

De Отто, Ignacio (1988): Derecho constitucional. Sistema de fuentes (segunda edición, Barcelona, Ariel), p. 315.

De Vergottini, Giuseppe (2010): Más allá del diálogo entre tribunales. Comparación y relación entre jurisdicciones (Trad. Pedro J. Tenorio Sánchez, Navarra, Civitas-Thomson Reuters), p. 332.

Del Toro Huerta, Mauricio Iván (2005): "La apertura constitucional al Derecho internacional de los derechos humanos en la era de la mundialización y sus consecuencias en la práctica judicial”, en Boletín Mexicano de Derecho Comparado (No 112), pp. 325-363.

DenNinger, Erhard (2004): “Derecho en 'desorden' global. Sobre los efectos de la globalización” (Trad. Joaquín Brage CAMAZANO), en Anuario Iberoamericano de Justicia Constitucional (No 8), pp. 117-130.

Esteve Pardo, José (2002): Autorregulación: génesis y efectos (Navarra, Aranzadi), p. 183.

FARIA, José Eduardo (2001): El Derecho en la economía globalizada (Trad. Carlos Lema AÑón, Madrid, Trotta), p. 288.

Fontanelli, Filippo (2011): "Santi Romano and L'ordinamento giuridico: The Relevance of a Forgotten Masterpiece for Contemporary International, Transnational and Global Legal Relations", en Transnational Legal Theory (Vol. II, No 1), pp. 67-117. 
Gambino, Silvio (2009): “I diritti fondamentali dell'Unione Europea fra 'trattati' (di Lisbona) e Costituzione”, en Rivista di Diritto Costituzionale, pp. 29-87. García-Andrade Gómez, Jorge (2012): "La reforma del artículo 135 de la Constitución española”, en RAP (No 187), pp. 31-66.

GarRido Gómez, M. Isabel (2010): Las transformaciones del Derecho en la sociedad global (Pamplona, Aranzadi/Thomson Reuters), p. 228.

Gordillo PÉrez, Luis I. (2012a): Constitución y ordenamientos supranacionales (Madrid, CEPC), p. 581.

(2012b): "Hacia una progresiva constitucionalización del poder sancionador del Consejo de Seguridad de la ONU”, en Estudios Constitucionales (Año 10, No 1), pp. 201-244.

Grossi, Paolo (2002): "Unità giuridica europea: un medioveo prossimo futuro?", en Quaderni Fiorentini, (No 31, I), pp. 39-57.

(2010): De la codificación a la globalización del Derecho (Trad. Rafael D. García Pérez, Pamplona, Aranzadi/Thomson Reuters), p. 394.

Guillén López, Enrique (2009): "Metodología del Derecho Constitucional Europeo. Un Derecho Constitucional para la integración política de Europa. Del pluralismo territorial al pluralismo ideológico", en $\operatorname{ReDCE}$ (No 12), pp. 151-170.

(2011): "The impact of the European Convention of Human Rights and the Charter of Fundamental rights of the European Union on Spanish constitutional law: Make a virtue of necessity", en AA.VV. Human rights protection in the European legal order: The interaction between the European and the national courts (Cambridge-Antwerp-Portland, Intersentia), pp. 309-341. HÄBERLE, Peter (1993): “Derecho Constitucional Común Europeo” (Trad. Emilio MikUnda), en REP (No 79), pp. 7-46.

(1996): Retos actuales del Estado Constitucional (Trad. Xabier ARzOZ SAntiesteban, Oñati, IVAP), p. 162.

(2000a): Pluralismo y Constitución. Estudios de Teoría Constitucional de la sociedad abierta (Trad. Emilio MiKUnd, Madrid, Tecnos), p. 295.

(2000b): Teoría de la Constitución como ciencia de la cultura (Trad. Emilio Mikunda, Madrid, Tecnos), p. 161.

(2001): El Estado constitucional (Trad. Héctor FiX-Fierro, México, UNAM, México), p. 339.

(2004): "Europa como comunidad constitucional en desarrollo" (Trad. Francisco Balaguer Callejón), en ReDCE (No 1), pp. 11-24. 
Herdegen, Matthias (2010): "La internacionalización del orden constitucional" (Trad. Luis Felipe Vergara Peña), en Anuario de Derecho Constitucional Latinoamericano (Vol. XVI), pp. 71-81.

Hillgruber, Christian (2004): "La integración del Derecho Internacional y del Derecho de la Unión Europea en el ordenamiento constitucional alemán” (Trad. M. Ángeles MarTín VidA), en ReDCE (No 1), pp. 115-138.

Huber, Peter M. (2013): "Estatalidad abierta: Un análisis comparado", en AA.VV. El Derecho Constitucional en el espacio jurídico europeo (Trad. Mariela MORALESAntoniazZI, Valencia, Editorial Tirant lo Blanch), pp. 69-141.

JACQUÉ, Jean-Paul (2007): "Droit constitutionnel national, Droit communautaire, CEDH, Charte des Nations Unies: l'instabilité des rapports de système entre ordres juridiques", en Revue Française de Droit Constitutionnel (No 69), pp. 3-37.

Koller, Werner y Biagnni, Giovanni (2002-2003): "La nueva Constitución federal suiza: una visión general de las novedades y los aspectos más destacados" (Trad. M. Ángeles MarTín VidA), en TRC (No 10-11), pp. 611-634.

LEBECK, Carl (2006): "National Constitutionalism, Openness to International Law and the Pragmatic Limits of European Integration - European Law in the German Constitutional Court from EEC to the PJCC”, en German Law Journal (Vol. VII, No 11), pp. 907-945.

Leguina Villa, Jesús (1993): "Notas sobre los principios de competencia y prevalencia en la legislación compartida”, en REALA (No 258), pp. 229-238.

Linde Paniagua, Enrique (2002): "Sistema de distribución de competencias y racionalización del sistema normativo", en RDUE (No 3), pp. 259-286.

Maduro, Miguel Poiares (2012): "Three Claims of Constitutional Pluralism”, en AA.VV. Constitutional pluralism in the European Union and beyond (Oxford, Hart Publishing), pp. 67-84.

Mahlmann, Matthias (2010): “The Politics of Constitutional Identity and its Legal Frame the Ultra Vires Decision of the German Federal Constitutional Court", en German Law Journal (Vol. XI, No 12), pp. 1407-1420.

Martín Y Pérez De Nanclares, José (2002): "La delimitación de competencias entre la Unión Europea y los Estados miembros: sobre el difícil equilibrio entre la flexibilidad, la eficacia y la transparencia”, en $R D C o E$ (No 12), pp. 343-391.

(2008): "La nueva regulación del régimen de competencias en el Tratado de Lisboa: especial referencia al control del principio de subsidiariedad", en AA.VV. El Tratado de Lisboa: la salida de la crisis constitucional (Madrid, Iustel), pp. 273-294. 
(2012): "El nuevo Tratado de Estabilidad, Coordinación y Gobernanza en la Unión Económica y Monetaria: reflexiones a propósito de una peculiar reforma realizada fuera de los Tratados constitutivos", en $R D C o E$ (No 42), pp. 397-431.

MarTín-Retortillo BAQUeR, Lorenzo (2004): La interconexión de los ordenamientos jurídicos y el sistema de fuentes del derecho (Madrid, Thomson/Civitas), $204 \mathrm{pp}$. Martines, Temistocle (1997): Diritto costituzionale (novena edición, Milano, Giuffrè Editore), p. 953.

Medinaceli Rojas, Gustavo (2012): "Criterios de interpretación en la nueva Constitución de Bolivia. Voluntad del constituyente versus jurisprudencia de la Corte Interamericana de Derechos Humanos", en Anuario de Derecho Constitucional Latinoamericano (No 18), pp. 139-150.

MenÉndeZ, Agustín José (2007): "Sobre los conflictos constitucionales europeos. Validez del derecho comunitario y legitimidad democrática de la Unión Europea”, en Anuario de Filosofía del Derecho (No 14), pp. 139-194.

Mercado Pacheco, Pedro (2012): "Libertades económicas y derechos fundamentales. La libertad de empresa en el ordenamiento multinivel europeo", en Cuadernos Electrónicos de Filosofía del Derecho (No 26), pp. 341-372. Fecha de la consulta: 19 de octubre de 2013. Disponible en http://ojs.uv.es/index. $\mathrm{php} / \mathrm{CEFD} / \mathrm{article} / \mathrm{view} / 1990 / 1526$.

Mirkine-GuetzévitCH, Boris (2009): Derecho constitucional internacional (Trad. Luis Legaz Y Lacambra, Madrid, Reus), 406 pp.

Modugno, Franco (1985): Legge - Ordinamento giuridico. Pluralità degli ordenamenti (Milano, A. Giuffrè Editore), p. 304.

Muñoz Machado, Santiago (2000): La regulación de la red. Poder y Derecho en internet (Madrid, Taurus), p. 281.

(2006): Tratado de Derecho administrativo y Derecho público general II (Madrid, Iustel), p. 1405.

Nogueira Alcalá, Humberto (2011): "El uso de las comunicaciones transjudiciales por parte de las jurisdicciones constitucionales en el Derecho comparado y chileno", en Estudios Constitucionales (No 2), pp. 17-76.

(2013a): "El control de convencionalidad y el diálogo interjurisdiccional entre tribunales nacionales y Corte Iberoamericana de Derechos Humanos", en ReDCE (No 19), pp. 221-270.

(2013b): "El uso del derecho y jurisprudencia constitucional extranjera y de tribunales internacionales no vinculantes por el Tribunal 
Constitucional chileno en período 2006-2011", en Estudios Constitucionales (No 1), pp. 221-274.

NúNEzz PoBlete, Manuel Antonio (2004): "Una introducción al constitucionalismo postmoderno y al pluralismo constitucional", en Revista Chilena de Derecho (Vol. XXXI, No 1), pp. 115-136.

(2010): "Sobre la declaración de inaplicabilidad de los Tratados internacionales. Un estudio en defensa de su fundamento y legitimidad", en Estudios Constitucionales (No 8), pp. 431-464.

Olivar JimÉnez, Martha Lucía (2009): "El Derecho del MERCOSUR y el Derecho Internacional - La lucha por independencia", en Revista electrónica de estudios internacionales (No 18), 24 pp. Fecha de consulta: 22 de febrero de 2013. Disponible en http://www.reei.org/index.php/revista/num18/articulos/ derecho-mercosur-derecho-internacional-lucha-independencia.

Ost, François y Van De Kerchove, Michel (2000): "De la pyramide au réseau? Vers un nouveau mode de production du droit?", en Revue Interdisciplinaire d'Études Juridiques (No 44), pp. 1-92.

PACE, Alessandro (2004): "Los retos del constitucionalismo en el siglo XXI", en ReDCE (No 2), pp. 161-180

Paulus, Andreas (2013): “Globalización en el Derecho constitucional” (Trad. Ignacio GutiérRez GutiérRez), en AA.VV. El Derecho constitucional de la globalización (Madrid, Fundación Coloquio Jurídico Europeo), pp. 63-112.

Pérez Luño, Antonio Enrique (2011): El desbordamiento de las fuentes del Derecho (Madrid, La Ley), 257 pp.

Pernice, Ingolf (1999): "Multilevel constitutionalism and the Treaty of Amsterdam: European constitution-making revisited", en Common Market Law Review (No 36), pp. 703-750.

(2012): "La dimensión global del Constitucionalismo Multinivel. Una respuesta global a los desafíos de la globalización” (Madrid, CEU Ediciones), p. 29. Fecha de consulta: 5 de marzo de 2013. Disponible en http://www.idee.ceu.es/Portals/0/Publicaciones/Docuweb\%20doc\%20\%20 61\%20UE.pdf.

Peters, Anne (2009): "Supremacy Lost: International Law Meets Domestic Constitutional Law", en Vienna Online Journal on International Constitutional Law (Vol. III, No 3), pp. 170-198. Fecha de la consulta: 8 de agosto de 2013. Disponible en http://ius.unibas.ch/uploads/publics/5435/20100219153347_4b7ea14b06261.pdf. 
Petersmann, Ernst-Ulrich (2006): "State Sovereignty, Popular Sovereignty and Individual Sovereignty: from Constitutional Nationalism to Multilevel Constitutionalism in International Economic Law?", en EUI Working Paper Law (No 45), p. 31. Fecha de la consulta: 8 de agosto de 2013. Disponible en http://papers.ssrn.com/sol3/papers.cfm?abstract_id=964147.

Pinto Bastos Junior, Luiz Magno (2007): "Utilización del derecho constitucional comparado en la interpretación constitucional: Nuevos retos a la teoría constitucional", en Estudios Constitucionales (No 2), pp. 252-274.

Pizzorusso, Alessandro (2002): Il patrimonio costituzionale europeo (Bologna, Il Mulino), p. 191.

(2005): Comparazione giuridica e sistema delle fonti del diritto (Torino, G. Giappichelli Editore), p. 313.

(2009): "La producción normativa en tiempos de globalización" (Trad. Augusto Aguilar Calahorro), en ReDCE (No 11), pp. 231-318.

Quindimil López, José Antonio (2012): "El acceso a Tribunales de Justicia supranacionales: aportes desde la Comunidad Andina y su incipiente ciudadanía comunitaria", en AA.VV. Tribunales en Organizaciones de Integración: Mercosur, Comunidad Andina y Unión Europea (Navarra, Thomson Reuters/Aranzadi), pp. 101-123.

Requejo Pagés, Juan Luis (1992): "Consideraciones en torno a la posición de las normas internacionales en el ordenamiento español”, en $R E D C$ (No 32), pp. 41-66.

(2000-2001): “Convenio Europeo y Tribunal Constitucional: La inviable diversidad de contenidos en los enunciados de derechos fundamentales", en Anuario Jurídico de La Rioja (No 6-7), pp. 377-386.

(2006): "Defensa de la Constitución nacional y constitucionalización de Europa. Inflacción de derechos y deslegación del ordenamiento", en Fundamentos: Cuadernos monográficos de teoría del estado, derecho público e historia constitucional (No 4), pp. 441-453.

Requena López, Tomás (2004): El principio de jerarquía normativa (Madrid, Thomson/Civitas), p. 359.

Rescigno, Giuseppe Ugo (2001): Corso di diritto pubblico (6a ed., Bologna, Zanichelli), p. 744.

Ridola, Paolo (2001): "Il principio di sussidiarietà e la forma di Stato di democracia pluralistica”, junto a Cervati, A. Antonio y Panunzio, Sergio P. , Studi sulla riforma costituzionale. Itinerari e temi per l'innovazione costituzionale in Italia (Torino, G. Giappichelli Editore), pp. 193-258. 
(2010): Diritto comparato e diritto costituzionale europeo, (Torino, G. Giappichelli Editore), p. 460.

Robles Morchón, Gregorio (2007): Pluralismo jurídico y relaciones intersistémicas. Ensayo de teoría comunicacional del Derecho (Navarra, Civitas/Thomson), p. 250.

Rodríguez-Izquierdo Serrano, Miryam (2011): Primacía y subsidiariedad en la Unión Europea (Madrid, CEPC), 444 pp.

Rosen, Mark D. (2008): “Contextualizing preemption”, en Northwestern University Law Review (Vol. CII, No 2), pp. 781-809.

Ruiz-Jarabo y Colomer, Dámaso (1993): El juez nacional como juez comunitario (Madrid, Fundación Universidad Empresa/Civitas), p. 204.

SAGÜÉs, Néstor Pedro (2010): "Obligaciones internacionales y control de convencionalidad", en Estudios Constitucionales (№ 1), pp. 117-136.

SÁnCHEZ BARRILAO, Juan Francisco (1998): "La regla de supletoriedad a propósito de la Sentencia del Tribunal Constitucional 61/1997, de 20 de marzo: Continuidad y renovación del Derecho estatal", en REP (No 99), pp. 281-302.

(2004a): "La supletoriedad del Derecho estatal como garantía en la ejecución del Derecho europeo por las Comunidades Autónomas", en $\operatorname{ReDCE}$ (No 1), pp. 241-268.

(2004b): "Relación entre el Derecho de la Unión Europea y el Derecho de los Estados miembros”, en ReDCE (No 2), pp. 127-148.

(2009): "Derecho europeo y globalización: mitos y retos en la construcción del Derecho Constitucional Europeo", en ReDCE (No 12), pp. 115-150.

(2012): "La constitucionalización de la integración regional europea.

¡Más Europa!: de vuelta a una Constitución para Europa, ante la situación de crisis de la Unión", en Estudios de Deusto (No 60/2), pp. 71-110.

(2013): "La crisis de la deuda soberana y la reforma del artículo 135 de la Constitución Española", en Boletín Mexicano de Derecho Comparado (No 137), pp. 679-712.

Sarmiento, Daniel (2012): “The Silent Lamb and the Deaf Wolves: Constitutional Pluralism, Preliminary References and the Role of Silent Judgments in EU Law", en AA.VV. Constitutional pluralism in the European Union and beyond (Oxford, Hart Publishing), pp. 286-317.

Schillaci, Angelo (2012a): Diritti fondamentali e parámetro di giudizio. Per una storia concettuale delle relazioni tra ordenamenti (Napoli, Jovene Editore), p. 534. (2012b): "Los derechos fundamentales en la interacción constitucional europea" (Trad. Sabrina RAGONE), en ReDCE (No 17), pp. 19-66. 
Scotт, Joanne (2011): “The Multi-Level Governance of Climate Change”, en Carbon and Climate Law Review (No 1), pp. 25-33.

SimonetTi, Hadrian (2009): Codici di autoregolamentazione e sistema delle fonti (Napoli, Jovene Editore), p. 230.

TAPIA VALDÉS, Jorge (2003): "Descentralización y subsidiariedad en la época de la globalización”, en Estudios Constitucionales (No 1), pp. 99-111.

(2008): "Poder constituyente irregular: los límites metajurídicos del poder constituyente originario", en Estudios Constitucionales (No 2), pp. 121-142.

TARRÉs Vives, Marc (2003): "Las normas técnicas en el Derecho Administrativo", en Documentación Administrativa ( $\mathrm{No}^{\mathrm{s}}$. 265-266), pp. 151-184.

Tejedor Bielsa, Julio C. (2000): La garantía constitucional de la unidad del ordenamiento en el Estado autonómico: competencia, prevalencia y supletoriedad (Madrid, Civitas), 223 pp.

Tornos Mas, Joaquín (1991): "Ley de Bases y Legislación de desarrollo: el problema de su articulación por modificación de la Ley de Bases: la cláusula de prevalencia, en REDC (No 33), pp. 29-46.

Tremolada Álvarez, Eric (2007): "Los pilares jurídicos de la Comunidad Andina: ¡elementos decisivos para su supervivencia?", en OASIS: Observatorio de Análisis de los Sistemas Internacionales (No 12), pp. 317-346.

Tribe, Laurence H. (2000): American Constitutional Law (tercera edición), (Vol. I, New York, Foundation Press), p. 1470.

TrstenjaK, Verica (2013): "National Sovereignity and the Principle of Primacy in EU Law and Their Importance for the Member States", en Beijing Law Review (Vol. IV, N. 2), pp. 71-76. Fecha de la consulta: 6 de julio de 2013. Disponible en http://www.scirp. org/journal/PaperInformation.aspx?PaperID=32507.

TusHnEt, Mark (2009): “The Inevitable Globalization of Constitutional Law”, en Virginia Journal of International Law (No 49/4), pp. 985-1006.

Twining, William (2009): "Institutions of Law from a Global Perspective: Standpoint, Pluralism and Non-State Law", en AA.VV. Law as Institutional Normative Order (Farnham, Ashgate), pp. 17-34.

Van Malleghem, Pieter-Augustijn (2013): "Pringle: A Paradigm Shift in the European Union's Monetary Constitution", en German Law Journal (Vol. XIV, No 1), pp. 141-168.

Vecchio, Fausto (2012a): "Primato del diritto europeo e controlimiti come tecniche di relazione tra gli ordinamenti", en Mediterraneam Journal of Human Rights (Vol. XVI), pp. 317-356. 
(2012b): Primazia del diritto europeo e salvaguardia delle identità costituzionali. Effetti asimmetrici dell'europeizzazione dei controlimiti (Torino, Giappichelli Editore), p. 262.

Vela Orbegozo, Bernardo (2007): "La encrucijada del proceso andino de integración”, en OASIS: Observatorio de Análisis de los Sistemas Internacionales (No 12), pp. 425-432.

Velasco Caballero, Francisco (2011): "Un ejemplo de funcionamiento de la "preemption" norteamericana: la regulación de la inmigración", en $R E A F$ (No 13), pp. 11-50.

Vigil Toledo, Ricardo (2012): "El reflejo de la jurisprudencia europea en los fallos del Tribunal de Justicia de la Comunidad Andina: aspectos teórico y pragmáticos", en AA.VV. Tribunales en Organizaciones de Integración: Mercosur, Comunidad Andina y Unión Europea (Navarra, Thomson Reuters/Aranzadi), pp. 215-235.

Von Bogdandy, Armin (2000): "The European Union as a Supranational Federation: A conceptual attempt in the light of the Amsterdam Treaty", en Columbia Journal of European Law (Vol. VI, No 1), pp. 27-54.

(2004): "Globalization and Europe: How to Square Democracy, Globalization, and International Law", en The European Journal of International Law (Vol. XV, No 5), pp. 885-906.

WAHL, Rainer (2006): “¿Cabe explicar la Unión Europea mediante conceptos fundamentales de Teoría del Estado?”, en TRC (o 18), pp. 105-129.

WaLKER, Neil (2009): "Multilevel Constitutionalism: Looking Beyond the German Debate”, en LSE 'Europe in Question' Discussion Paper Series (No 8), p. 36. Fecha de la consulta: 8 de agosto de 2013. Disponible en http://www.lse. ac.uk/europeanInstitute/LEQS/LEQSPaper8Walker.pdf.

Xiol Ríos, Juan Antonio (2009): "Notas sobre la jurisprudencia”, junto a FerReres COMELlA, Víctor, El carácter vinculante de la jurisprudencia (segunda edición, Madrid, Fundación Coloquio Jurídico Europeo), pp. 81-133.

Zagrebelsky, Gustavo (2012): La virtud de la duda: una conversación sobre ética y Derecho con Geminello Preterossi (Trad. José Manuel Revuelta, Madrid, Trotta), p. 136.

\section{Normas jurídicas citadas}

Carta de los Derechos Fundamentales de la Unión Europea, de 12 de diciembre de 2007. 
Constitución de Alemania, de 23 de mayo de 1949.

Constitución de Australia, de 9 de julio de 1900.

Constitución de Bolivia, de 7 de febrero de 2009.

Constitución de España, de 29 de diciembre de 1978.

Constitución de Irlanda, de 1 de julio de 1937.

Constitución de los Estados Unidos de Norteamérica, de 17 de septiembre de 1787.

Constitución de México, de 5 de febrero de 1917.

Constitución de Suiza, de 18 de abril de 1999.

Convención Americana sobre Derechos Humanos, de 22 de noviembre de 1969.

Convenio Europeo para la protección de los Derechos Humanos, de 4 de noviembre de 1950 .

Estatuto de Autonomía de Andalucía, Ley Orgánica No 2/2007, de 19 de marzo de 2007 (España).

Ley No 13/1999, de 21 de abril, de adhesión de España a diversos Acuerdos del Fondo Monetario Internacional (España).

Ley No 32/2003 General de Telecomunicaciones, de 3 de noviembre de 2003 (España).

Tratado Constitutivo del Mecanismo Europeo de Estabilidad (MEDE), de 2 de febrero de 2012.

Tratado de Funcionamiento de la Unión Europea, 13 de diciembre de 2007 (texto consolidado de 2010).

Tratado de la Unión Europea, de 7 de febrero de 1992 (texto consolidado de 2010).

Tratado por el que se establece una Constitución para Europa, de 29 de octubre de 2004 (ratificación inconclusa).

Reglamento (CE) 343/2003, de determinación del Estado responsable del examen de una solicitud de asilo (Dublín II), de 18 de febrero de 2003.

\section{Jurisprudencia citada}

\section{Corte Interamericana de Derechos Humanos}

Sentencia Atala Riffo y niñas vs. Chile, de 24 de febrero de 2012.

\section{Tribunal Constitucional español}

Sentencia 36/1991, Cuestiones de inconstitucionalidad acumuladas 1.001/1988, 291/1990, 669/1990, 1.629/1990 y 2.151/1990, de 14 de febrero de 1991 . 
Declaración 1/2004, Requerimiento 6603/2004, de 13 de diciembre de 2004.

Sentencia 155/2005, Recursos de inconstitucionalidad acumulados 73/1999 y 3247/1999, de 9 de junio de 2005.

Sentencia 66/2011, Recurso de amparo 2942/2007, de 16 de mayo de 2011.

Sentencia 198/2012, Recurso de inconstitucionalidad 6864/2005, de 6 de noviembre de 2012.

Sentencia 135/2013, Recurso de inconstitucionalidad 964/2004, de 6 de junio de 2013.

\section{Tribunal Europeo de Derechos Humanos}

Sentencia Dudgeon vs. United Kingdom, Application No 7525/76, de 23 de septiembre de 1981.

Sentencia Salgueiro da Silva Mouta vs. Portugal, Application No 33290/96, de 21 de diciembre de 1999.

Sentencia M.S.S. vs. Bélgica y Grecia, Application No 30696/09, de 21 de enero de 2011.

\section{Tribunal de Justicia (Unión Europea)}

Sentencia Van Gend en Loos, Asunto 26/62, de 5 de febrero de 1963.

Sentencia Costa/ENEL, Asunto 6/64, de 15 de julio de 1964.

Sentencia Internationale Handelsgesellschaft, Asunto 11/70, de 17 de diciembre de 1970.

Sentencia Nold, Asunto 4/73, de 14 de mayo de 1974.

Sentencia Simmenthal II, Asunto 106/77, de 9 de marzo de 1978.

Sentencia Hauer, Asunto 44/79, de 13 de diciembre de 1979.

Sentencia Grimaldi, Asunto C-322/88, de 13 de diciembre de 1989.

Sentencia Comisión v. Alemania, Asunto C-61/94, de 10 de septiembre de 1996.

Sentencia Kadi, Asuntos acumulados C $-402 / 05$ y C $-415 / 05$, de 3 de septiembre de 2008.

Dictamen 1/09, de 8 de marzo de 2011.

Sentencia Pringle, Asunto C-370/12, de 27 de noviembre de 2012.

Sentencia Akerberg Fransson, Asunto C-617/10, de 26 de febrero de 2013. 


\section{Tribunal Supremo de Canadá}

Sentencia Same-Sex Marriage, 2004 SCC 79, de 9 de diciembre de 2004.

Tribunal Supremo de los Estados Unidos de Norteamérica

Sentencia Lawrence vs. Texas, 539 U.S. 558 (2003), de 26 de junio de 2003. 